\title{
VARIAÇÃO E MUDANÇA LINGUÍSTICA: PANORAMA E PERSPECTIVAS DA SOCIOLINGUÍSTICA VARIACIONISTA NO BRASIL
}

\author{
LANGUAGE VARIATION AND CHANGE: OVERVIEW AND PERSPECTIVES OF VARIATIONIST \\ SOCIOLINGUISTICS IN BRAZIL
}

\author{
Ana Cristina Biondo Salomão* \\ Universidade Estadual Paulista - UNESP/IBILCE, São José do Rio Preto, BR
}

\begin{abstract}
RESUMO: Desde a década de 1970 inúmeros grupos de pesquisa surgiram no Brasil na área da Sociolinguística, buscando investigar a linguagem relacionando-a a fatores sociais que distinguem diferentes comunidades de fala para a desconstrução da ideia de homogeneidade linguística. Muitos dos trabalhos desenvolvidos têm suas bases na sociolinguística variacionista (LABOV, 2008[1972]), para a qual a variação e a mudança são inerentes às línguas, como um fenômeno cultural motivado por fatores linguísticos e extralinguísticos. Pretendemos, aqui, retomar os caminhos percorridos pela Sociolinguística desde seu início como ciência, atendo-nos principalmente à corrente variacionista, revisitando seus conceitos-chave e sua metodologia, e apresentar um panorama dos trabalhos desenvolvidos nesta linha de pesquisa no Brasil na atualidade.

PALAVRAS-CHAVE: sociolinguística variacionista; variação e mudança linguística; grupos de pesquisa.
\end{abstract}

\begin{abstract}
Since the 1970s many research groups have emerged in Brazil in the area of Sociolinguistics, seeking to investigate language in relation to social factors that distinguish different speech communities to deconstruct the idea of linguistic homogeneity. Many of the works have been based on variationist sociolinguistics (LABOV, 2008 [1972]), for which variation and change are inherent to languages, i.e., heterogeneous structures are part of the speakers' linguistic competence, as a cultural phenomenon motivated by linguistic and extralinguistic factors. Our aim, in this article, is to address the paths of Sociolinguistics since its beginning as a science, focusing mainly on the variationist strand, by recalling its key-concepts and methodology, and to present an overview of the research works conducted in Brazil in this field nowadays.

KEYWORDS: variationist sociolinguistics; language variation and change; research groups.
\end{abstract}

\begin{abstract}
Uma das características mais importantes das línguas humanas e mais relevantes à questão do ensino da língua materna é a diversidade linguística. Este é um ponto básico nas pesquisas e teorias sociolinguísticas e, em princípio, não precisamos de nenhuma pesquisa acadêmica formal para reparar na existência desta diversidade. Ela é evidente pela experiência de todo mundo; entretanto, em muitas sociedades, como é o caso da sociedade brasileira, a representação sociocultural da língua de certo modo oblitera essa percepção, fazendo crer que a língua de verdade não varia - ou, numa exacerbação idealizada, faz crer que a língua não deveria variar. (GUY; ZILLES, 2006, p. 42).
\end{abstract}

\section{INTRODUÇÃO}

Os sociolinguistas atualmente têm se voltado para a análise das relações entre a estigmatização linguística e a mobilidade social. De acordo com Mollica (2004, p.13), o preconceito linguístico tem sido um ponto bastante debatido na área, uma vez que se nota ainda a predominância de "práticas pedagógicas assentadas em diretrizes maniqueístas do tipo certo/errado", que tomam como referência o padrão culto. Para a autora, os estudos sociolinguísticos "oferecem valiosa contribuição no sentido de destruir preconceitos linguísticos e de relativizar a noção de erro, ao buscar descrever o padrão real que a escola, por exemplo, procura desqualificar e banir como expressão linguística natural e legítima”.

A proliferação de estudos na área da Sociolinguística tem sido uma grande contribuição para que, por meio da construção de um panorama das comunidades de fala existentes no Brasil, possa ser fomentada a desconstrução da ideia de homogeneidade linguística. 
Nossa intenção neste artigo é elaborar uma retrospectiva da Sociolinguística como ciência, enfocando a corrente variacionista, sua gênese e desenvolvimento, e apresentar um levantamento dos trabalhos feitos na atualidade dentro dos microcontextos estudados por diversos grupos de pesquisa que proliferaram a partir nas últimas décadas na vasta extensão do território brasileiro.

\section{A ORIGEM DA SOCIOLINGUÍSTICA}

A Sociolinguística como um campo específico de estudo se desenvolveu, sobretudo a partir da década de 1960, que representa o marco do início dos estudos mais sistemáticos na área. Shuy (2003) conta que para se ter uma ideia de quão recente era o termo "sociolinguística" a terceira edição de 1961 do Dicionário Internacional New Webster não trazia esta palavra. Entretanto, suas origens se situam bem antes. Paulston e Tucker (2003) afirmam que o termo "sociolinguística" foi cunhado em 1939 no título do artigo de Thomas C. Hodson, Sociolinguistics in India publicado no periódico Man in India. Foi inicialmente usado pelo linguista Eugene Nida na segunda edição de seu Morphology (1949, p. 152), mas há também a atribuição do termo a Haver Currie, que usou o termo em um trabalho apresentado em uma conferência em 1949 e depois em uma publicação no Southern Speech Journal em 1952.

Segundo Paulston e Tucker (2003), quando a Sociolinguística se tornou popular como um campo de estudo no final dos anos 60, dois nomes foram dados para o estudo da intersecção e interação entre linguagem e sociedade: sociolinguística e sociologia da linguagem. Segundo os autores, a princípio os termos eram usados como sinônimos, mas após algum tempo uma distinção passou a ser feita. De modo sintético, explicava-se tal diferença do seguinte modo: enquanto a sociolinguística estaria preocupada principalmente com uma descrição maior e mais ampla da linguagem, tendo em foco o efeito da sociedade sobre a língua (realizada principalmente por linguistas e antropólogos), a sociologia da linguagem enfocaria a explicação e previsão de fenômenos de linguagem no comportamento social, ou seja, o efeito da língua na sociedade (conduzida principalmente por cientistas sociais, assim como por alguns linguistas).

Shuy (2003) explica as orígens da Sociolinguística norte-americana, colocando suas bases na Linguística, na Antropologia e na Sociologia. Para o autor, da perspectiva da linguística pode-se buscar, assim como o faz Koerner (1988), uma passagem intelectual do conceito de fala - que se inicia com a visão de Whitney (1867) de que ela não é uma possessão pessoal, mas sim social, ou seja, embora iniciada pelos atos do indivíduo, é forjada pela comunidade - perpassando as visões de Saussure, Meillet, Martinet, Weinreich, Labov. Do ponto de vista antropológico, o autor afirma que a Sociolinguística adviria da antiga Linguística Antropológica. Para ele, essa posição é favorecida pelo fato de que os sociolinguistas estendem a descrição e análise da língua incluindo aspectos da cultura na qual é usada. Entretanto, a Antropologia clássica enfoca o comportamento humano, seus padrões e princípios, enquanto que a Sociolinguística examina em profundidade aspectos da linguagem no contexto social. A contribuição da Sociologia, para o autor, estaria também relaciona à disciplina "sociologia da linguagem", citada anteriormente, ministrada por sociólogos e linguistas, numa busca de entrelaçar a descrição da estrutura e organização de comportamentos sociais com o estudo da linguagem.

Para Shuy, a maioria dos sociólogos de orientação linguística enfrentou problemas departamentais, uma vez que o tempo e esforço que teriam de investir para fazer um trabalho bem fundamentado na linguística se chocavam com as exigências do departamento e corria o risco de sacrificar outros aspectos do conhecimento sociológico exigido por esse campo. Naturalmente, o mesmo poderia ser dito de antropólogos e linguistas em relação aos seus respectivos campos de estudo. Deste modo, para que o campo da Sociolinguística pudesse se beneficiar plenamente da combinação de tais disciplinas, os insights etnográficos dos antropólogos, a teoria social e métodos da sociologia e as informações de base linguística tinham de ser mescladas. Assim, os anos 60 se revelaram como um momento de grande efervescência para a Sociolinguística, por meio da união de estudiosos dessas três áreas do conhecimento para determinar como cooperar através das linhas disciplinares tradicionais. 
A formalização inicial de uma escola teórica sociolinguística teria acontecido em uma reunião, em maio de 1964, organizada por William Bright, na Universidade de Los Angeles (UCLA), com a participação de 26 linguistas, cuja produção científica focava-se, em sua maioria, no campo da Linguística social. Entre os participantes estavam William Labov, Dell Hymes, John Gumperez, Charles Fergunson, entre outros, unidos pela vontade difusa de apresentar uma alternativa ao crescente prestígio e predomínio mundial de uma Linguística cada vez mais formal, representada pelas pesquisas de Chomsky, voltadas para a produção de modelos explicativos abstratos sobre a competência linguística (CARBONI, 2008).

À época da conferência, uma série de estudiosos estava investigando a relação entre linguagem e sociedade, incluindo Henry M. Hoenigswald, John Gumperz, Einar Haugen, Raven I. McDavid, Jr., Dell Hymes, John Fischer, William Samarin, Paul Friedrich e Charles Ferguson. Os trabalhos dos participantes advinham de tradições de pesquisa bastante diferentes, como a geografia linguística, línguas em contato, mudanças históricas, etnografia e planejamento linguístico, e as palavras-chave que estabeleciam uma ligação entre elas eram "linguagem e sociedade" e "sociolinguística".

William Bright, encarregado da publicação das atas (Proceedings of the UCLA Sociolinguistics Conference, 1966), tentou sintetizar as diferentes contribuições e definiu o objeto de estudo deste campo como sendo a diversidade linguística, cujos fatores condicionantes, a seu ver, estariam relacionados à identidade social do falante, à identidade social do destinatário e ao contexto (MONTEIRO, 2000). Bright, nesse momento, concebeu a Sociolinguística como uma abordagem anexa dos fatores da língua, que viria a complementar a Linguística ou a Sociologia e a Antropologia, mas tal subordinação pouco a pouco começou a desaparecer com Labov, um dos mais conhecidos sociolinguistas. Durante muitos anos, Labov se recusou a usar o termo sociolinguística, pois acreditava que ele implicaria que poderia existir uma teoria ou prática social linguística fecunda que não fosse social (LABOV, 2008[1972]).

$\mathrm{Na}$ verdade, desde o nascimento da linguística moderna, com Ferdinand Saussure, diferentes teorias e sistemas de descrições têm sido elaborados buscando delimitar esse campo da ciência de modo restritivo, eliminando de suas preocupações tudo aquilo que não é a estrutura abstrata. Podemos dizer que a Sociolinguística permitiu, assim, o estudo científico de fatos linguísticos excluídos até então do campo dos estudos da linguagem, devido a sua diversidade e consequente dificuldade de apreensão. Através de pesquisas de campo, a Sociolinguística registra, descreve e analisa sistematicamente diferentes falares, elegendo, assim, a variedade linguística como seu objeto de estudo.

\subsection{O escopo da Sociolinguística}

Monteiro (2000) afirma que, pela própria extensão e imprecisão do conceito de Sociolinguística, não se conseguiu ainda demarcar bem o que deve ou não fazer parte de seu escopo. Ele aponta, baseando-se em Baylon (1991), que em sua fase inicial a Sociolinguística tinha como foco a descrição das diferentes variedades que coexistem dentro de uma comunidade de fala, relacionando-as com as estruturas sociais; já hoje ela "engloba praticamente tudo o que diz respeito ao estudo da linguagem em seu contexto social" (BAYLON, 1991 apud MONTEIRO, 2000, p. 26).

Monteiro (2000) explica que a Sociolinguística pode ser compreendida a partir de duas perspectivas diferentes de estudo: a macrossociolinguística e a microssociolinguística. A primeira trata das relações entre a sociedade e as línguas como um todo, discutindo questões como as consequências do multilinguismo no desenvolvimento econômico e as prováveis políticas linguísticas que um governo pode adotar; a segunda analisa os efeitos dos fatores sociais sobre as estruturas linguísticas, utilizando-se para tanto de testes estatísticos na tentativa de determinar as pressões que condicionam a aplicação de uma dada regra variável.

Neste artigo, enfocaremos a segunda perspectiva, comumente denominada "Sociolinguística Variacionista" ou "Teoria da variação", corrente cujo grande expoente é William Labov. Os métodos utilizados por ele para coletar dados das variedades do inglês faladas em Nova York, publicados em "The Social Stratification 
of English in New York City” (1966), assim como seus estudos sobre as características do inglês afroamericano, tiveram uma influência fundamental na dialetologia social.

Com metodologia bem delimitada, a Sociolinguística Variacionista baseia-se em pressupostos teóricos que permitem ver regularidade e sistematicidade por trás do aparente caos da comunicação no dia-a-dia, procurando demonstrar como uma variante se implementa na língua ou desaparece.

\section{A SOCIOLINGUÍSTICA VARIACIONISTA}

O modelo teórico-metodológico da Sociolinguística Variacionista, também denominada Sociolinguística Quantitativa, por operar com números e tratamento estatístico dos dados coletados, é atribuído a William Labov, que, insistindo veementemente na relação entre língua e sociedade, criou um modelo de análise que possibilitasse a sistematização da variação existente na língua falada.

Nas palavras de Labov (2008[1972], p.13-14):

...existiam barreiras ideológicas para o estudo da língua na vida diária. Primeiramente, Saussure tinha enunciado o princípio de que os sistemas estruturais do presente e as mudanças históricas do passado tinham de ser estudados separadamente (1949:124). Este princípio tinha sido consistentemente erodido por Martinet (1955) e outros que encontraram estrutura nas mudanças passadas, mas pouco progresso fora feito na localização da mudança nas estruturas presentes. A segunda barreira ideológica afirmava explicitamente que a mudança sonora não podia, em princípio, ser observada diretamente. Bloomfield defendia a regularidade da mudança sonora contra a evidência irregular do presente declarando (1933:364) que quaisquer flutuações que pudéssemos observar seriam apenas casos de empréstimo dialetal. Em seguida, Hockett observou que, embora a mudança sonora fosse lenta demais para ser observada, a mudança estrutural era rápida demais (1958:457). O estudo empírico da mudança linguística estava, portanto, eliminado do programa da linguística do século XX.

Os primeiros estudos conduzidos por Labov nessa linha de pesquisa foram sua dissertação de mestrado sobre o inglês falado na ilha de Martha's Vineryard (centralização de ditongos), no estado de Massachussets, e sua tese de doutorado sobre a estratificação do inglês falado na cidade de Nova York (a variável / r /), ambos orientados por Uriel Weinreich, na Universidade de Colúmbia.

Uma das grandes diferenças entre a sociolinguística variacionista e a linguística estruturalista é o objeto. Na primeira, o objeto é a fala, enquanto que na segunda, os fenômenos da fala atingem apenas a substância material das palavras, não seu significado, e, portanto, não se constituem como seu objeto de estudo. Outra diferença essencial é a compreensão da variação e das mudanças linguísticas, uma vez que para os variacionistas as mudanças advêm do comportamento social enquanto que para os linguistas estruturalistas elas são internas ao sistema.

Em seu texto clássico, Weinreich, Labov e Herzog (2006[1975]) afirmam que estruturas heterogêneas são parte da competência linguística, ou seja, necessárias para o funcionamento real de qualquer língua e o indivíduo tem capacidade para codificar e decodificar essa heterogeneidade. Assim, para os variacionistas, a variação e a mudança são inerentes às línguas. A variação não é vista como um efeito do acaso, mas como um fenômeno cultural motivado por fatores linguísticos e por extralinguísticos, e não é assistemática. Labov (2008[1972]), afirmava que devemos determinar qual estrutura social corresponde à dada estrutura linguística e como mudanças na estrutura social se traduzem em mudanças na estrutura linguística. No caso de sua pesquisa em Martha's Vineyard, por exemplo, Labov observou que a comunidade sofreu influências sociais dramáticas provocadas por veranistas do continente e que os habitantes "nativos", ressentindo-se de tal invasão cultural e econômica, marcavam a pronúncia dos ditongos como forma de demarcar seu espaço, sua identidade, sua cultura, seu perfil de comunidade e de grupo social, e concluiu que o estilo articulatório seria objeto de avaliação social. Portanto, variáveis linguísticas particulares poderiam ser afetadas pela tendência geral rumo ao favorecimento de uma postura articulatória, sob a influência das forças sociais. 
Nesse sentido, a análise sociolinguística enfoca fundamentalmente o processo de interação fala/sociedade, justificando-se pela necessidade de compreender os fatores que possam influenciar a operação de uma ou de outra variante, na busca de estabelecer uma sistematização ao processo de variação linguística.

De fato, variante, variável e variedade são alguns dos termos-chave nesta linha de pesquisa. O termo variante é utilizado nos estudos de Sociolinguística para designar as formas que estão sofrendo variação, ou seja, uma ou mais formas usadas ao lado de outra na língua sem que se verifique mudança no significado básico. O conjunto das variantes é denominado "variável linguística”, ou seja, a forma, o traço ou construção linguística que é o próprio fenômeno variável tomado como objeto de estudo pelo investigador. A sociolinguística entende que o emprego das variantes não é aleatório, mas influenciado por grupos de fatores de natureza social (internos à língua) ou estrutural (externos à língua), os quais podem exercer pressão sobre os usos (LABOV, 2008[1972]). E variedade é o termo que corresponde, grosso modo, ao termo dialeto. Para Monteiro (2000), a expressão variedade linguística foi criada para evitar as conotações negativas dos termos língua e dialeto. Para ele, a variedade pode ser muito maior do que uma língua ou muito menor do que um dialeto.

\subsection{Metodologia da pesquisa na Sociolinguística variacionista}

A pesquisa na Sociolinguística Variacionista busca apreender a sistematicidade da variação, seu encaixamento linguístico e social e uma possível relação com a mudança linguística por meio de análises quantitativas de um corpus, escolhido a partir de certas características sociais correlacionadas a uma variável linguística - que pode ser fonético-fonológica, morfossintática, entre outras. O equacionamento da questão da variação pressupõe respostas para cinco problemas (WEINREICH; LABOV; HERZOG, 2006[1975]):

a) Fatores condicionantes - busca-se compreender quais são as condições para a mudança em dada estrutura, que podem advir de fatores de ordem social e de ordem linguística.

b) Encaixamento da variação - busca-se atentar para outras mudanças associadas a determinadas mudanças ou variação das formas em observação na matriz dos concomitantes linguísticos e extralinguísticos e nos desdobramentos da estrutura social.

c) Avaliação das mudanças - busca-se estudar os possíveis efeitos da variação sobre a estrutura linguística, sobre a eficiência comunicativa e sobre um amplo conjunto de categorias nãorepresentacionais (inclusive interacionais, discursivas e pragmáticas) envolvidas na fala.

d) Transição - busca-se compreender os estágios intervenientes entre dois estados da língua: como um falante aprende uma forma alternante, tempo em que as duas formas co-existem, tempo em que uma das formas prevalece sobre a outra.

e) Implementação - busca-se analisar os fatores responsáveis pela implementação da mudança e a razão pela qual as mudanças em um aspecto estrutural ocorrem em determinada língua em um dado momento, mas não em outra língua com o mesmo aspecto, ou na mesma língua, em outras épocas.

Essa corrente trabalha com dados estatísticos, que são tratados quantitativa e qualitativamente. A dimensão quantitativa dos estudos variacionistas é conteúdo de relativa complexidade. Naro (2004) apresenta a evolução dos modelos matemáticos adotados por Labov na quantificação dos dados obtidos em seus primeiros estudos, os quais passaram de um modelo aditivo (da soma dos fatores contextuais de aplicação de uma variante) a modelos multiplicativos de aplicação e não aplicação, criados por Henrietta Cedergren e David Sankoff em 1974, nos quais se propôs uma interpretação probabilística que substituiu frequências por probabilidades. Em 1978, com Pascale Rousseau e David Sankoff, chegou-se ao modelo logístico, o qual engloba propriedades dos anteriores e acrescenta a noção de peso relativo. Este último é o modelo que vem sendo utilizado até hoje nos estudos variacionistas, denominado análise da regra variável, que consiste em um tipo de análise multivariada que objetiva separar, quantificar e testar a significância dos efeitos de fatores contextuais em uma variável linguística (GUY; ZILLES, 2007). 
Trabalha-se com o falante-ouvinte real, em situações reais de linguagem. O sociolinguista busca coletar um grande número de dados por meio de gravações de amostras de fala de um número considerável de informantes, por meio de entrevista de experiência pessoal, para que o envolvimento emocional com o assunto os leve a produzir um discurso informal e espontâneo. Labov (2008[1972], p.110) discute a técnicas para se estender o aspecto formal da entrevista, assim como a importância de ir além da situação para que se consiga "capturar a fala cotidiana que o informante usará tão logo a porta se feche atrás de nós: o estilo que ele usa para discutir com a mulher, repreender os filhos ou conversar com os amigos", uma vez que o objetivo da pesquisa linguística na comunidade deve ser o de descobrir como as pessoas falam quando não estão sendo sistematicamente observadas. Para o autor, alguns procedimentos usados pelo entrevistador podem desviar a atenção do falante e permitir que o "vernáculo emerja" (p.244), como por exemplo: criar intervalos e pausas nos quais a pessoa presuma que não está sendo entrevistada, ou envolvê-la em assuntos que recriem fortes emoções. Labov sugere também outras formas de coleta de dados que podem se mostrar confiáveis e práticas, como entrevistas rápidas e anônimas (como em sua investigação nas lojas de departamentos), observações assistemáticas em locais públicos (o autor alerta para algumas distorções embutidas neste tipo de coleta, como o favorecimento de pessoas menos discretas e que falam mais alto), gravações advindas de meios de comunicação em massa (pode haver instantes de transmissão direta nos quais há menos monitoramento da fala, como na cobertura de desastres, por exemplo, entretanto há que se considerar que em geral o estilo é ainda mais formal do que obteríamos em uma entrevista face-a-face).

Entre os informantes escolhidos, geralmente, estão as pessoas nascidas e criadas na comunidade a ser estudada ou aqueles que vivem nela desde os 5 anos de idade. Segundo Guy e Zilles (2007), uma das melhores formas de garantir que haja representatividade é o uso de uma amostra aleatória que dê a cada informante ou dado potencial existente na população total igual probabilidade de serem incluídos na amostra. Para se estimar a relação entre amostra e o universo de onde foi retirada usam-se as medidas de significância, comuns em pesquisas de base quantitativa.

Primeiramente, o investigador tem de delimitar o fenômeno linguístico variável, levantando todas as possibilidades de produção que estão em variação. Posteriormente, ele deve lançar hipóteses sobre as variáveis condicionadoras (linguísticas e sociais) que podem estar influenciando a escolha de uma ou de outra forma variante, baseando-se tantos nos dados coletados, na teoria linguística e na estrutura social da comunidade estudada. É importante, que o investigador identifique os grupos de fatores, tanto estruturais como sociais, com os quais irá trabalhar antes de submeter os dados a uma análise computacional, por meio de um pacote de programas (alguns dos mais utilizados são o VARBRUL e o GOLDVARB) que faz os cálculos de frequência.

Guy e Gilles (2007) explicam que os programas de análise multivariada são preferíveis, pois permitem a construção de um modelo completo e específico dos processos e efeitos que não aparecem num simples cálculo de porcentagens. ${ }^{1}$ Tendo as informações fornecidas após os cálculos feitos pelo programa, procedese, então, à interpretação, que envolve a complexa tarefa de inter-relacionar os princípios estatísticos e as teorias sociais e linguísticas que formam a base da concepção do trabalho, definição das hipóteses, dos grupos de fatores, etc. O resultado da análise das variantes pode produzir duas situações: a existência de estabilidade entre variantes, denominada variação; ou a competição entre as variantes com aumento de uso de uma delas, chamada mudança em curso.

\section{A SOCIOLINGUÍSTICA VARIACIONISTA NO BRASIL}

Os pressupostos teórico-metodológicos da Sociolinguística vêm sendo trabalhados em diversos centros de pesquisa do mundo. Segundo Carboni (2008), a Sociolinguística Laboviana predomina hoje, sobretudo nas

1 Para aprofundamento no instrumental de análise quantitativa na sociolinguística variacionista ver Guy e Zilles (2007). 
Américas do Sul e do Norte, regiões onde tende a ser considerada como a Sociolinguística propriamente dita. Na Europa, nos idos de 1970, principalmente na França, segundo a autora, os estudos inspirados pela Sociolinguística foram muitos e dinâmicos, realizados em uma perspectiva interdisciplinar, entre os departamentos de Linguística e História. De acordo com a autora, os pesquisadores de diversos países europeus naquele momento deram preferência aos princípios teóricos e opções metodológicas de uma Sociolinguística mais qualitativa do que quantitativa "devido à necessidade de resolução de problemas práticos decorrentes das situações de diglossia e de bilinguismo ou de discriminação de línguas e dialetos minoritários em países e regiões com repertórios plurilíngues e pluridialetais complexos, como é o caso da maioria dos países europeus" (p. 89).

No Brasil, segundo Cezario e Votre (2008), as pesquisas nessa linha começaram a ser desenvolvidas na década de 1970, por meio da atuação dos seguintes grupos de pesquisadores: o grupo do projeto Mobral Central, o grupo do projeto da Norma Urbana Oral Culta do Rio de Janeiro (Nurc) e do projeto Censo da Variação Linguística no Estado do Rio de Janeiro (Censo), tendo como coordenadores os professores Miriam Lemle, Celso Cunha e Anthony Naro, respectivamente. Os mesmos autores citam ainda outros diversos grupos que em várias universidades brasileiras, seguem os pressupostos teórico-metodológicos da Sociolinguística, como o Programa de Estudos sobre o Uso da Língua (Peul), continuidade do Projeto Censo, o próprio Nurc - na Universidade Federal do Rio de Janeiro (UFRJ); o projeto de Variação Linguística da Região Sul do Brasil (Varsul) - na Universidade Federal de Santa Catarina (UFSC), na Universidade Federal do Rio Grande do Sul (UFRS), na Universidade Federal do Paraná (UFPR) e na Pontifícia Universidade Católica do Rio Grande do Sul (PUC-RS).

Diversos trabalhos de pesquisa foram conduzidos por estes grupos com o objetivo de descrever as formas variantes do português do Brasil e de explicar os fatores linguísticos e extralinguísticos que favorecem/desfavorecem as variantes linguísticas, revelando estreita correlação entre a complexidade social e os processos de variação. Segundo Mollica e Roncarati (2001), a maioria dos pesquisadores nessa área hoje

congrega-se em Projetos Integrados, formando pólos de atuação que permitem estabelecer uma rede complementar de resultados, referendando-os ou contestando-os. Ao adotar perspectivas diferentemente priorizadas, em grupo ou isoladamente, os estudiosos recobrem um painel de conhecimentos sobre as dimensões geodialetal, sócio-estratificada, histórico-social e discursivo-cultural. (MOLLICA; RONCARATI, 2001, p. 46).

Segundo as autoras, já existe expressivo acervo de pesquisas dessa natureza sobre a fala e a escrita, que objetivam analisar a variação, aquisição e mudança linguística, abrangendo fenômenos morfossintáticos, fonológicos e discursivo-pragmáticos, investigando as atitudes e crenças linguísticas implicadas na variação linguística e identificando estratégias argumentativas envolvidas no texto escrito e suas marcas linguísticas.

Pretendemos, na próxima seção, traçar um panorama dos grupos de pesquisa que atuam em diferentes regiões do Brasil na atualidade buscando investigar e descrever a variação linguística no país.

\subsection{Grupos de pesquisa que trabalham com a sociolinguística variacionista no Brasil na atualidade}

Pela extensão geográfica do Brasil, é de se imaginar que coexistam diferentes dialetos regionais: o falar carioca é claramente diferente do falar gaúcho ou paulista, ou do nordestino (todos apresentando também diversidades, ou seja, não são blocos homogêneos). Dentro das comunidades existem também diferenças entre as várias faixas da população: entre pessoas de várias classes sociais ou níveis de renda e de escolaridade, entre grupos étnicos, entre faixas etárias, entre homens e mulheres.

Como dito na seção anterior, alguns grupos pioneiros deram início às pesquisas em Sociolinguística Variacionista na tentativa de estudar a variedade linguística do português no Brasil. Hoje, existem vários grupos de pesquisa, em todas as regiões do país. Paiva e Scherre (1999, p.202-203) apontaram um grande número de grupos de pesquisa variacionista e não variacionista que despontaram e cresceram até o final da 
década de 1990 no Brasil, contribuindo para nossa compreensão acerca dos condicionamentos linguísticos e sociais da modalidade culta e não culta do português do Brasil:

Incorrendo no risco da enumeração, devemos lembrar aqui o projeto Competências básicas do português (Lemle \& Naro, 1977), o VARSUL - Variação linguística urbana da Região Sul - (Fernandes, 1996:89), o VALPB - Variação linguística no Estado da Paraíba - (Hora, 1998), o LUAL - A língua usada em Alagoas (Moura, 1997); Dialetos sociais cearenses (Aragão \& Soares, 1996), o projeto de estudo da confluência dialetal na nova capital brasileira (Bortoni, 1984), o grupo de estudos Discurso e Gramática (Martelotta et alii, 1996) e a recente empreitada da Gramática do português falado (Castilho, 1990), todos mais voltados para a linguagem dos grandes centros urbanos. Destacam-se também pesquisas que focalizam dialetos rurais (Rodrigues, 1974; Jeroslow, 1974; Nina, 1980; Veado, 1982), ou comunidades específicas, como as pesqueiras do Estado do Rio de Janeiro, projeto APERJ - Altas etnolinguístico dos pescadores do Estado do Rio de Janeiro (Brandão \& Vieira, 1998), ou comunidades isoladas brancas (Isensee, 1964; Callou, 1998) e comunidades isoladas negras (Ferreira, 1994; Careno, 1992; Vogt \& Fry, 1997). Ampliando os estudos de comunidades isoladas negras e de áreas específicas do interior baiano, assume corpo o projeto Vestígios de dialetos crioulos em comunidades afro-brasileiras (Baxter \& Lucchesi, 1997) e emerge o projeto A língua portuguesa no semi arido baiano (Almeida \& Carneiro, 1998). Perscrutando aspectos estruturais e sociais na linha do tempo, destaca-se o Programa para a história da língua portuguesa (PROHPOR) (Mattos e Silva, 1996) e cria-se o Projeto para a história do português brasileiro (Castilho, 1998). Não podemos deixar de lembrar também as conquistas substanciais do grupo coordenado pelo saudoso Fernando Tarallo, com a sua proposição de uma Sociolinguística Paramétrica, levada à frente por um número significativo de pesquisadores, que com muito contribuiu para o conhecimento das características do português brasileiro e das mudanças em curso nessa variedade (cf., por exemplo, Tarallo, 1983; 1989; Roberts \& Kato, 1993; Cerqueira, 1990; Pagotto, 1992; Nunes, 1995; Duarte, 1995; 1998; Ramos 1997;1998/2000; Cyrino, 1997; Corrêa, 1998). (PAIVA; SCHERRE, 1999, p.202-203).

Segundo as autoras, os diferentes trabalhos apresentam especificidades teórico-metodológicas, entretanto, sua convergência de objetivos mais amplos "tem possibilitado acúmulo considerável de conhecimento acerca da multidialetação diatópica e diastrática, da sistematicidade do uso linguístico e dos processos de mudança na variedade brasileira do português" (p. 203).

Uma vez que o levantamento das autoras cobriu os trabalhos realizados na década de 1990, buscamos agora fazer um mapeamento dos principais grupos de pesquisa que trabalham com pressupostos teóricos da teoria da variação e mudança surgidas a partir do ano 2000. Para tal, fizemos um levantamento dos grupos formados na última década no país², que é apresentado na tabela abaixo, contendo o nome do grupo, seu(s) líder (es), a instituição a que pertence e seus objetivos, enumerado em ordem cronológica de acordo com o ano de formação:

Tabela 1 - levantamento dos grupos de pesquisa:

\begin{tabular}{|c|c|}
\hline Gru & Objetivos \\
\hline $\begin{array}{l}1 \text { - De } \\
\text { Portu } \\
\text { Ano d } \\
\text { Lidere } \\
\text { Maria } \\
\text { Institu } \\
\text { - UFP }\end{array}$ & $\begin{array}{l}\text { Descrever e analisar dados linguísticos do português falado e escrito no extremo sul do Brasil. } \\
\text { Estudos Prioritários: fonologia, morfologia e sintaxe; variação e mudança linguística. } \\
\text { Base de Dados : VARX (Variação Linguística por classe social em Pelotas) - } 90 \text { entrevistas- e } \\
\text { BDS Pampa (Dados de Pelotas, Jaguarão, Arroio Grande e Tavares) - } 72 \text { entrevistas. } \\
\text { Dentre os projetos de pesquisa vinculados ao grupo destacam-se: "A concordância verbal } \\
\text { variável de segunda pessoa do singular em Pelotas", "A concordância de primeira pessoa do } \\
\text { plural no Extremo Sul do Brasil", já concluídos; e "A concordância verbal variável de terceira } \\
\text { pessoa do plural em Pelotas", "Fontes do português brasileiro", "Sociolinguística educacional: } \\
\text { utilização de aspectos linguísticos do banco de dados VarX como subsídios à educação", } \\
\text { "Concordância verbal com sujeito posposto", "Formação do plural no português brasileiro", em } \\
\text { "Um banco de textos constituído por redações do vestibular da UFPel", em andamento. }\end{array}$ \\
\hline $\begin{array}{l}2 \text { - Atlas Linguístico-Et } \\
\text { Região Sul do Brasil (A } \\
\text { Ano de formação: } 2000\end{array}$ & $\begin{array}{l}\text { O Grupo de Pesquisa ALERS reúne-se em torno do Projeto de mesmo nome, constituído de } \\
\text { equipes de pesquisadores das três universidades federais do sul do Brasil (UFRGS, UFSC e } \\
\text { UFPR), para estudar a variação linguística do português falado no sul do Brasil. Trata-se de um } \\
\text { projeto na área de geolinguística que visa a apresentar, sob a forma de um atlas linguístico, as }\end{array}$ \\
\hline
\end{tabular}

$2 \mathrm{O}$ levantamento foi feito com base em nosso conhecimento de alguns grupos atuantes na região sudeste e sul, acrescido de uma pesquisa na base de dados do CNPq (http://dgp.cnpq.br/buscaoperacional/) durante junho e julho de 2011, utilizando-nos das seguintes palavras-chave: sociolinguística, sociolinguística variacionista, sociolinguística quantitativa, sociolinguística laboviana e teoria da variação e mudança. Outras informações foram obtidas na plataforma lattes, nos sites oficiais dos programas de pós-graduação em linguística e dos grupos e associações de estudos da linguagem no país. 
Líderes: Cléo Vilson Altenhofen e José Luiz da Veiga Mercer

Instituição: Universidade de Caxias do Sul UCS

\section{3 - História Social do Português}

Ano de formação: 2000

Líderes: Jania Martins Ramos e Lorenzo Teixeira Vitral

Instituição: Universidade Federal de Minas Gerais - UFMG

\section{4 - Vertentes}

Ano de formação: 2001

Líder: Dante Eustachio Lucchesi Ramacciotti

Instituição: Universidade Federal da Bahia UFBA

\section{5 - Problemas da cultura medieval} ibérica: aspectos literários

Ano de formação: 2001

Líder: Ângela Tonelli Vaz Leão

Instituição: Pontifícia Universidade Católica de Minas Gerais - PUC Minas

6 - GIEL - Grupo Interinstitucional de Estudos de Lingua(gem): usos, contatos e fronteiras

Ano de formação: 2002

Líderes: Maria Jussara Abraçado de Almeida e Monica Maria Guimarães Savedra

Instituição: Universidade Federal Fluminense - UFF

\section{7 - Acervos Documentais: Memória} Linguística e Literária

Ano de formação: 2002

Líder: Monica Guieiro Ramalho de Alkmim

Instituição: Universidade Federal de Ouro Preto - UFOP mais significativas variantes diatópicas (fônicas, morfossintáticas e léxico-semânticas) da língua portuguesa falada pelas classes de menos escolaridade no sul do Brasil. A coleta e transcrição dos dados resultou em um banco de cerca de 300.000 dados orais de 275 pontos de inquéritos rurais. Em 2002, concluiu-se a publicação dos volumes 1 e 2. Em 2006, concluiu-se a cartografia dos dados semântico-lexicais, perfazendo 374 cartas que irão constituir um novo volume 2 sendo os volumes anteriores reunidos em uma 2 a edição. Com a conclusão da editoração e revisão desses volumes, em 2010, tem-se quase como certa a sua publicação para 2011. 0 Grupo contribui, ainda, para uma compreensão mais ampla do plurilinguismo da região, descrevendo e mapeando aspectos derivados dos inúmeros contatos linguísticos do português com línguas de adstrato (indígena, afrobrasileiro, de imigração ou de fronteira). Sua produção insere-se em uma rede internacional de pesquisadores que inclui o intercâmbio e colaboração com projetos como o Atlas Linguístico do Brasil (ALiB - www.ufba.br/alib), o Atlas LinguísticoContatual das Minorias Alemãs na Bacia do Prata: Hunsruckisch - www.ufrgs.br/projalma), Atlas linguístico Diatópico y Diastrático del Uruguay (ADDU) e o Atlas Linguístico Guarani-Românico (ALGR). Ao longo da sua realização, o Projeto central do Grupo recebeu financiamentos do CNPq, FINEP e FAPERGS.

O trabalho desenvolvido por este grupo de pesquisa tem como objeto a mudança linguística, e se desenvolve em duas frentes. A primeira visa a fornecer análise formal de fenômenos linguísticos. A segunda visa a fazer levantamento de dados, com base em corpora, de modo a chegar a uma cronologia. Segundo os pesquisadores do grupo, o objetivo é tratar do fenômeno da mudança sem dissociar fatores condicionadores internos e externos. Este grupo desenvolve pesquisa vinculada a três projetos maiores: (i) "Para a História do Português Brasileiro", (ii) "A Construção de um dialeto: a língua portuguesa em Minas Gerais nos séculos XVIII, XIX e XX" (FAPEMIG 2007-atual); e (iii) Novos Clíticos (CNPq 1998-atual), nos quais buscam identificar e descrever novas variáveis (você e suas variantes; senhor e suas variantes), propor uma cronologia do português brasileiro escrito, e analisar fenômenos presentes no português nãopadrão: redução fonológica de pronomes; redobro pronominal; pronomes 'eu', 'ele' em posição objeto e indeterminação de sujeito pelo pronome 'eles'.

0 grupo Vertentes pretende contribuir com 0 avanco do conhecimento acerca da realidade sociolinguística do português popular do Estado da Bahia, bem como de sua formação sóciohistórica, desenvolvendo as seguintes ações: 1) constituição em meio digital de acervos de fala das diversas variedades da língua popular do interior do estado da Bahia e de sua capital, a cidade de Salvador; 2) transcrição ortográfica dessas amostras de fala; 3) elaboração de análises coordenadas de aspectos relevantes da morfossintaxe nessas diversas variedades do português popular, atentando para as seguintes questões: os processos de variação e mudança induzidos pelo contato entre línguas; e os processos de nivelamento a partir dos grandes centros urbanos. Os resultados dessas análises têm sido publicados em: 1) comunicações em congressos da área; 2) artigos em revistas especializadas; 3) página do Projeto na Internet; 4) livro "O Português Afro-Brasileiro". O objetivo final do Grupo é constituir um panorama sociolinguístico do português popular do Estado da Bahia, integrando, no plano linguístico, a diversidade étnica da sociedade brasileira e produzindo subsídios para políticas de educação pública mais adequadas à realidade cultural do país. Desde agosto de 2002, o Projeto Vertentes também conta com bolsas de Iniciação Científica da FAPESB, do CNPq e do PIBIC/UFBa, para os alunos de graduação que atuam no Projeto na pesquisa de campo e nas atividades de digitalização, edição e transcrição das entrevistas.

Este projeto de pesquisa tem por objeto a obra monumental intitulada Cantigas de Santa Maria, coleção de 420 poemas do século XIII, de Afonso X, o Sábio, acompanhados de partituras musicais e de iluminuras (em geral seis por poema). $O$ objetivo da pesquisa é a análise temática dos poemas, do ponto de vista literário e cultural, segundo a edição crítica de Walter Mettmann. Essa análise dos textos de Mettmann tem a rara possibilidade de confronto com os originais, já que a PUC Minas possui os facsímiles dos dois códices já editados (Barcelona: Edilán,1979), a partir dos quatro existentes. $O$ projeto tem grande comprometimento também com a linha Variação e mudança linguística. 0 projeto atual resulta da fusão de dois outros (um literário e o outro linguístico), que já vinham sendo desenvolvidos em conjunto por estudantes das duas áreas de concentração. A sua produtividade se traduz em vários trabalhos apresentados em congressos nacionais e internacionais, além de 13 dissertações de Mestrado e 04 teses de Doutorado, defendidas entre fins de 1992 e 2005

O Grupo Interinstucional de Estudos Linguísticos (GIEL) UFF, UFRJ, PUC-Rio, UFJF constituise um grupo de pesquisa voltado para questões relacionadas ao uso da língua. Sob tal perspectiva, estão sendo desenvolvidos trabalhos em descrição linguística, gramaticalização, variação e mudança; contato linguístico; políticas linguísticas, identidade e representação. 0 grupo busca reunir e incentivar projetos de pesquisa que abordem questões afetas à língua(gem), no que diz respeito ao seu funcionamento em situações e condições diversas de uso e de interação. Busca, ainda, estabelecer discussão acerca de modelos teóricometodológicos diferentes, visando melhor entender e/ou descrever os fenômenos linguísticos investigados, entre os quais: relação língua e sociedade, a estabilidade e heterogeneidade linguística, os fatores condicionantes da variação fonológica, morfossintática e discursivopragmática, a variação no indivíduo e na comunidade, e a interface socilionguística / gramaticalização.

O objetivo deste grupo é identificar marcas e características próprias da linguagem falada/escrita em Minas Gerais, através do estudo da fala/escrita da região, buscando identificar variáveis linguísticas e processos de mudança e explicá-los quanto à transição, implementação, avaliação e encaixamento 


\section{Padrões Sonoros Emergentes}

Ano de formação: 2002

Líderes: Thaïs Cristófaro Alves da Silva e Christina Abreu Gomes

Instituição: Universidade Federal de Minas Gerais - UFMG

\section{9 - Grupo de Estudos em Linguística Histórica}

Ano de formação: 2002

Líderes: Rosane de Andrade Berlinck e Clotilde de Almeida Azevedo Murakawa

Instituição: Universidade Estadual Paulista Júlio de Mesquita Filho - UNESP/FCLAR

\section{0 - Grupo de Estudos Linguísticos São Bento}

Ano de formação: 2002

Líderes: Andréa Maristela Bauer Tamanine e Maria da Graça Albino de Oliveira

Instituição: Universidade da Região de Joinville - UNIVILLE

\section{1 - Para uma História do Português}

Brasileiro: $\mathbf{5 0 0}$ anos de Língua

Portuguesa

Ano de formação: 2002

Líderes: Dinah Maria Isensee Callou Afranio Gonçalves Barbosa

Instituição: Universidade Federal do Rio de Janeiro - UFRJ

\section{2 - Vozes da Amazônia}

Ano de formação: 2002

Líderes: Regina Celia Fernandes Cruz e Soélis Teixeira do Prado Mendes

Instituição: Universidade Federal do Pará UFPA

\section{3 - Projeto ALIP}

Ano de formação: 2002

Líderes: Sebastião Carlos Leite Gonçalves e Luciani Ester Tenani

Instituição: UNESP - São José do Rio Preto

\section{4 - Projeto NURC/SP- Núcleo USP}

Ano de formação: 2003

Líderes: Dino Fioravante Preti e Marli padrões sonoros estáveis nas línguas naturais. A ideia central é avaliar o comportamento dos elementos básicos de análise - ou seja, os sons - em contraste com outras unidades potenciais de análise - como a sílaba ou a palavra. Os pressupostos teóricos deste grupo sedimentam-se nos modelos da Difusão Lexical (Wang, 1969), da Fonologia de Uso (Bybee, 2001) e da Teoria de Exemplares (Johnson, 1997), Pierrehumbert (2001, 2003). Fatores sociais relevantes à implementação de mudanças sonoras são estudados a partir da perspectiva variacionista (Labov, 1994) e/ou da relação entre indivíduo e redes sociais (Milroy \& Milroy, 1985). O papel do indivíduo na implementação de padrões sonoros é também considerada (Oliveira, 1999). 0 pressuposto básico assumido é que a estrutura sonora emerge a partir do uso da língua. Os trabalhos do grupo visam contribuir para uma melhor compreensão da linguagem enquanto fenômeno social.

As atividades do Grupo 'Linguística Histórica' estão ligadas ao LEDiP - Laboratório de Estudos Diacrônicos do Português. As pesquisas desenvolvidas pelo Grupo estão organizadas em torno de quatro grandes áreas de concentração: Fonologia, Morfologia, Sintaxe, Lexicologia e Lexicografia. Além de projetos individuais, são desenvolvidos presentemente projetos coletivos: (a) VARIAÇÃO E MUDANÇA DO PORTUGUÊS: MORFOLOGIA E SINTAXE, sob a responsabilidade de Rosane de Andrade Berlinck; (b) FONOLOGIA DO PORTUGUÊS ARCAICO, coordenado por Gladis Massini-Cagliari. Um marco do início das atividades do Grupo foi a celebração do Convênio de Cooperação Acadêmico-Científica entre a FCL/UNESP e a Universidade de Évora, Portugal, em maio de 1998. Da parte da FCL, a coordenadora do convênio é a Profa. Dra. Clotilde de Almeida Azevedo Murakawa. Da parte portuguesa, a coordenadora é a Profa. Dra. Maria Filomena Gonçalves. O Convênio foi renovado e tem abrigado novas ações conjuntas: a participação da Profa. Dra. Ma. Filomena Gonçalves, no Projeto Dicionário Histórico do Português, o intercâmbio de pós-graduandos.

Entre as diferentes temáticas, o trabalho do grupo visa: 1. contribuir com a gramática do português brasileiro falado, especialmente no âmbito dos pronomes pessoais e do bilinguísmo português/alemão em Santa Catarina, por meio da identificação de fenômenos de variação linguística no PB e seus contextos linguísticos e extralinguísticos; 2. contribuir com uma nova postura do professor de língua materna diante da norma escolar. Esta consideração também se fundamenta no desenvolvimento de pesquisas na área de gêneros textuais (além da dialetologia e da sociolinguística, em que o maior objetivo é avaliar e aplicar as teorias existentes no trabalho de sala de aula no Ensino Fundamental); 3. analisar do discurso jurídico, em que a semântica das relações de poder é analisada. Segundo os pesquisadores, a formação heterogênea do grupo de pesquisa tem favorecido pesquisas em âmbitos diferenciados, apesar das ligações teóricas serem sempre a tônica das abordagens.

Nascido de uma conjuntura científica que congregou, no final do milênio, diversas equipes e projetos, por todo o país, o Projeto vem desenvolvendo uma investigação coordenada sobre os caminhos da língua portuguesa no Brasil, sob três perspectivas: o da organização de corpora diacrônicos de variados tipos de textos manuscritos e impressos; o da análise de mudanças gramaticais; e o da história social. Segundo os pesquisadores, pesquisas recentes já anunciaram algumas "explicações" mais ou menos seguras das causas das diversidades horizontais e verticais, ao longo dos séculos XVI-XX, o que representa um avanço no conhecimento da língua portuguesa, tanto na perspectiva externa, em que se articulam fatos de ocupação territorial, de sucessivas distribuições demográfico-linguísticas, prevalências e desaparecimento de línguas, quanto da interna, em que se examina a evolução das estruturas linguísticas. Seu objetivo neste projeto é dar uma contribuição concreta para a elaboração de uma sociolinguística histórica.

O grupo tem como objetivo verificar a coocorrência de variantes no falar interiorano da Amazônia paraense. No caso específico do projeto analisam-se variações de natureza fonética, tais como: a nasalização, a alternância [o] >[u], a alternância [i] > [e] no uso dos clíticos, a ocorrência de ideofones. 0 grupo visa ainda identificar causas linguísitcas e/ou sociais para tais variações e contribuir para a preservação e recuperação da identidade linguística paraoara. 0 grupo já conseguiu implantar o primeiro laboratório de ciência e tecnologia da fala da região norte (Edital Proint 2004-2005 UFPA), e sua coordenadora é a primeira Bolsista Produtividade do CNPq da área de Linguística da UFPA. Os pesquisadores envolvidos contaram ainda com apoio de agências de fomento como a Fulbright/CAPES para visita de pesquisador ao exterior $\mathrm{e}$ bolsas PIBIC.

O projeto ALIP foi uma iniciativa concebida no interior do Grupo de Pesquisa em Gramática Funcional, (GPGF) do IBILCE/UNESP, entre os anos de 2002 e 2003, em razão do interesse dos membros do grupo em trabalhos de descrição do português falado e escrito. Originado do projeto "O português falado na região de São José do Rio Preto: constituição de um banco de dados anotado para 0 seu estudo", 0 projeto ALIP (http://www.iboruna.ibilce.unesp.br/interna.php?Link=corpo.php\&corpo=37) tem por objetivo constituir-se de base para a descrição do português falado no interior paulista, mais especificamente na região noroeste do Estado de São Paulo. Os informantes que cederam suas amostras de fala, que hoje compõem o banco de dados denominado lboruna, são provenientes das seguintes cidades: Bady Bassit (BAD), Cedral (CED), Guapiaçu (GUA), Ipiguá (IPI), Mirassol (MIR), Onda Verde (OND) e São José do Rio Preto (SJP). O objetivo do projeto foi constituir um banco de dados com amostras de fala sistematicamente controladas por variáveis sociais, e representativas, portanto, do dialeto falado no interior paulista, em razão de este ser ainda pouco conhecido, em bases científicas, por seus usuários, e pelos próprios linguistas. O projeto teve apoio da Fundação de Amparo à Pesquisa do Estado de São Paulo - FAPESP (Proc. 03/08058-6).

Dando continuidade ao projeto de estudo da "norma linguística urbana culta" (NURC), o núcleo USP, liderado por Dino Preti, visa pesquisar a variação linguística na língua oral e escrita, incluindo a variável faixa etária, gênero e grau de escolaridade. Nos anos de 2003/06, o grupo publicou os seguintes livros organizados por Dino Preti: "Léxico na língua oral e na escrita" (2003), "Diálogos na fala e na escrita" (2005), "Oralidade em diferentes discursos" (2006), 


\section{Quadros Leite}

Instituição: Universidade de São Paulo USP

15 - Observatório de Linguagem do Sul e Sudeste do Pará

Ano de formação: 2003

Líder: Eliane Pereira Machado Soares

Instituição: Universidade Federal do Pará UFPA

16 - Núcleo de Estudos da Linguagem

Ano de formação: 2003

Líderes: Jaciara Rondon Gonçalves e Juscéia Aparecida Veiga Garbelini

Instituição: Fundação Universidade Federal do Tocantins - UFT

\section{7 - Descrição sócio-histórica do} português de Belo Horizonte

Ano de formação: 2004

Líder: Marco Antonio de Oliveira

Instituição: Pontifícia Universidade Católica de Minas Gerais - PUC Minas
"Oralidade em textos escritos" (2009). Em 2008, o grupo publicou a obra "Cortesia verbal" (São Paulo: Humanitas, 2008) e participou de vários eventos com palestras, mesas-redondas e comunicações, tendo como objeto o corpus do Projeto NURC/SP.

Projeto vinculado ao Atlas Geo-sociolinguístico do Estado do Pará (ALIPA), cujos objetivos são elaborar o "Atlas geo-sociolinguístico do Pará", elaborar o "Atlas geo-sociolinguístico da Mesorregião Metropolitana de Belém e do Nordeste Paraense" e identificar, analisar e mapear a variação linguística (variação fonética, morfossintática e lexical). Este projeto abrange as dez cidades correspondentes à pesquisa urbana do ALIPA.

A coleta de dados foi feita através de um questionário (de natureza fonética - fonológico) de 159 perguntas aplicado a 4 informantes por cidade, estratificados por sexo, idade e escolaridade até a $4^{\text {a }}$ série.

Um dos objetivos do grupo é estudar 8 comunidades quilombolas das 15 reconhecidas pelo Estado de Tocatins: Morro São João situada no município de Santa Rosa; Redenção em Natividade; Barra de Aroeira em Santa Teresa; Cocalinho em Santa Fé; Malhadinha e Córrego Fundo, ambas situadas em Brejinho de Nazaré; Mumbuca, situada em Mateiros; e Prata, situada no município de São Félix. Visando investigar a variação linguística, etnolinguística, diversidades regionais e étnicas, o grupo realiza diagnóstico socioeconômico, mapeamento sociolinguístico e estudos das variações sociais.

0 projeto em questão pretende realizar uma pesquisa em larga escala, visando descrever 0 português de Belo Horizonte, levando em conta não apenas as características estruturais desta variedade do português brasileiro, mas também a sua formação sócio-histórica. Os dois primeiros anos foram dedicados à descrição do componente fonológico. Segundo o grupo, o português de Belo Horizonte possui características especiais, tanto por sua composição linguística, seu estágio de desenvolvimento (+/- 110 anos de formação) e sua composição socia (tanto em termos da migração interna, dentro do estado de Minas Gerais, quanto em termos das levas de imigrantes oriundos de outros países, principalmente Portugal e Itália). Na primeira fase do projeto, focalizou-se o sistema fonológico do português belo-horizontino, utilizando, como aparato descritivo, os modelos fonológicos pertinentes, e situando a análise numa perspectiva variacionista, uma vez que foram examinados fenômenos de variação fonológica. A partir da descrição do sistema fonológico do português belo-horizontino, discutiram-se, também, algumas questões teóricas que têm sido levantadas na literatura recente sobre variação e mudança linguística, principalmente aquela que envolve o confronto entre os modelos neogramático e difusionista como modelos explicativos da mudança. Em sua segunda fase o projeto irá se concentrar em problemas relativos à morfossintaxe do português. Esta fase, iniciada já em 2007, focaliza as seguintes variáveis: 1- Reestruturação do sistema pronominal, em termos das mudanças já processadas e em termos dos casos de variação atuais; 2- As orações relativas, que variam entre (a) uma forma que inclui um pronome relativo, (b) uma variante que contém um pronome anafórico e, (c) uma forma tradicionalmente chamada de 'cortadora; 3- A concordância nominal, e 4- A concordância verbal.

Os projetos desenvolvidos dentro deste grupo de pesquisa vinculam-se tanto à linha de pesquisa "Linguística dos gêneros e tipos textuais" como também a discussões e projetos que têm sido desenvolvidos por pesquisadores da linha "Estudo da variação e mudança linguística". As investigações vinculadas a esta segunda linha têm como objetivo contribuir para a elucidação de fatos do português, seja sob o aspecto sincrônico ou diacrônico. 0 grupo interage tanto com o GREF (Grupo de Estudos Funcionalistas da Linguagem), bem como com outros grupos da Faculdade de Letras da UFMG. Ainda, desde a sua fundação, em 2004, até a fase atual, 0 grupo vem interagindo produtivamente com grupos de pesquisa sediados em outras universidades do país, tais como a UNESP (São José do Rio Preto e Araraquara), a UFJF e a UFF, além de ter promovido vários eventos sobre o tema Oralidade e Escrita na Faculdade de Letras da UFMG. Gerais - UFMG

\section{9 - Núcleo de Estudos Linguísticos do Cariri}

Ano de formação: 2004

Líderes: Sandra Espínola dos Anjos Almeida e Thiago Gil Lessa Alves

O Núcleo de Estudos Linguísticos do Cariri-NELC preocupa-se em descrever o perfil linguístico do falante caririense e em estudar, sincrônica e diacronicamente, fenômenos relacionados ao português, como a relação fala/escrita, oralidade/letramento, variação e mudança linguística, bem como o estudo das línguas clássicas, tais como grego e latim. No momento também tem se detido no estudo de língua estrangeira, analisando o papel do aprendiz no processo de aprendizagem.

Instituição: Universidade Regional do Cariri URCA

\section{0 - Descrição Sócio-Histórica das Vogais do Português (do Brasil)}

Ano de formação: 2005

Líderes: Seung Hwa Lee e Marco Antonio de Oliveira

Instituição: Universidade Federal de Minas Gerais - UFMG

\section{1 - GEPS-Grupo de Estudos e Pesquisas} Sociolinguísticas e Sócio-Culturais

Ano de formação: 2005

Líderes: Maria do Socorro Pessoa e Fábio Santos de Andrade
O grupo visa realizar uma investigação multidisciplinar - sócio-histórica e linguística - para descrever as realizações fonéticas das vogais nos dialetos do sul ao norte do Brasil. Os objetivos específicos são: 1) Contribuir para a documentação e constituição de um banco de dados relativo aos dialetos envolvidos, tendo em vista sistematizar/digitalizar a documentação sobre esses dialetos; 2) Descrever e analisar os aspectos fonéticos e fonológicos; 3) Descrever e analisar os aspectos sociolinguísticos dos dialetos envolvidos; 4) Contribuir para a formação de profissionais qualificados para atuar na área de Sociolinguística e Linguística Histórica, assim como em Linguística/Fonologia; 5) Realizar uma experiência de cooperação entre diferentes pesquisadores e diferentes instituições; 6) Discutir variação inter- e intradialetal; 7) Discutir mudança linguística; 8) Discutir tipologicamente variação/mudança linguística.

O GEPS tem a Lingua (gem), a Cultura e a Educação como eixos condutores e divide-se em linhas de pesquisas para alcançar a identidade-sócio-linguístico-cultural de comunidades imigrantes, migrantes, indígenas, afro-descendentes, povos da floresta, povos ribeirinhos e comunidades sócio-minoritárias na Amazônia. Assim, são investigadas as marcas sociais linguísticas, educacionais e culturais dos povos amazônicos/amazônidas. Pesquisam-se as atitudes linguísticas das comunidades referidas em relação à enorme variação dialetal da língua portuguesa existente, em contato com outras línguas e dialetos, registrando-se as influências 
Instituição: Universidade Federal de Rondônia - UNIR que este contato provoca no ensino de língua(s) e na educação local. São discutidos os seguintes temas: preconceito linguístico, políticas educacionais, políticas linguísticas, formação de professores para o ensino da língua portuguesa materna e não materna, com vistas à valorização da heterogeneidade e da diversidade linguístico-cultural existente na região. VARIAÇÃO LINGUISTICA URBANA DO SUL DO PAÍS (VARSUL - http://www.varsul.org.br/) instala-se em quatro sedes: UFRGS, UFSC, UFPR, PUCRS, esta incluída em 1990. 0 projeto nasceu com os objetivos básicos de oferecer: subsídios para a descrição do português falado no país; condições para teste e desenvolvimento de teorias linguísticas; condições para formação de novos pesquisadores; subsídios para programas educacionais, promovendo o conhecimento e o respeito às variedades linguísticas. De acordo com os pesquisadores, em 1988, começou a coleta de dados no Rio Grande do Sul, e, em 1990, nos demais Estados. As amostras ficaram assim organizadas: Rio Grande do Sul: Porto Alegre, Flores da Cunha, Panambi e São Borja Santa Catarina: Florianópolis, Blumenau, Chapecó e Lages. Paraná: Curitiba, Londrina, Irati e Pato Branco. Com respeito à metodologia do levantamento de dados, seguiu-se a linha laboviana, inspirando-se a transcrição das entrevistas no trabalho realizado pela equipe do Projeto Censo do Rio de Janeiro que teve a orientação de Anthony Naro. Evidentemente escreveu-se uma versão particular, em virtude da diversidade étnica e sociocultural que caracteriza os três Estados que compõem a amostra. O Banco VARSUL vem sendo constantemente ampliado com o acréscimo de novas amostras em todas as sedes. À amostra básica, constituída de informantes sem curso superior, distribuídos por grau de escolaridade, sexo e faixa etária (acima de 25 anos), outras vêm sendo acrescidas, contemplando novas regiões, diferentes faixas etárias, bem como níveis de escolaridade. A análise dos fenômenos linguísticos da língua portuguesa é conduzida com base na perspectiva da variação/mudança seja da Sociolinguística, sob a ótica do princípio uniformitarista, seja do Funcionalismo (sobretudo givoniano), sob a ótica da gramaticalização.

0 Grupo de Estudos em Linguagem, Interação e Sociedade - GELINS busca instituir e consolidar a prática de pesquisa linguística no agreste central sergipano com as seguintes linhas de atuação: 1) investigação dos fenômenos da linguagem; 2) formação de recursos humanos; e 3) constituição de banco de dados linguísticos. O grupo conduz a análise de processos de variação e mudança linguística envolvendo formas verbais relacionadas à expressão do tempo passado, em uma abordagem que articula pressupostos teórico-metodológicos da sociolinguística variacionista e do funcionalismo linguístico de orientação norte-americana. Toma-se por base uma função semântico-discursiva de expressão do tempo passado desempenhada por formas variantes com matizes de significado, e que busca respaldo na sociolinguística e no funcionalismo para explicar a emergência e as trajetórias de mudança pelas quais passam as formas, delineadas por evidências quantitativas, contribuindo para a descrição e análise da variação e mudança linguística nos níveis gramaticais mais altos. A análise toma como amostra a comunidade de fala de Itabaiana/SE, com o Banco de Dados do Grupo de Estudos em Linguagem, Interação e Sociedade (GELINS).

O Projeto ALERS pretende constituir-se de um atlas linguístico regional no país que possibilita a comparação de áreas em esfera interestadual. 1) No âmbito do ALERS regional, publicaram-se os dois primeiros, de uma coleção prevista para 4 volumes, 2) No âmbito do ALERS/SC -setor do Estado de Santa Catarina, a exemplo dos outros dois estados da Região, está sendo implantado, na UFSC, um banco de dados a fim de propiciar pesquisas conexas com o projeto, glossários, monografias, estudo de falares locais e regionais. Constam deste banco: 340 horas de gravação em fita cassete, com a fala de 96 informantes, sendo 80 da zona rural e 16 da zona urbana; e 37 volumes de transcrição fonética manuscrita das fitas. No segundo semestre de 2007, a equipe do ALERS de Santa Catarina, sob a coordenação do Prof. Dr. Felício Wessling Margotti, integrou-se aos trabalhos do Atlas Linguístico do Brasil - ALIB, tendo realizado os inquéritos nos municípios de Blumenau, Itajaí, Lages, Tubarão. Em 2008, foram realizados os inquéritos em Criciúma/SC, São Borja/RS e Uruguaiana/RS. Instituição: Universid
Catarina - UFSC

\section{5 - Grupo de Estudos Linguísticos do Acre}

O grupo objetiva descrever e analisar o português brasileiro, com enfoque especialmente no ecossistema linguístico do Acre, considerando sua história interna e externa, buscando também uma interface com a educação.

Ano de formação: 2007

Líderes: Vicente Cruz Cerqueira e Paula

Tatianne Carréra Szundy

Instituição: Universidade Federal do Acre -

UFAC

26 - LINGUAGEM, ESCOLA E SOCIEDADE

A primeira grande atividade do grupo foi a pesquisa A Variação Linguística em Teresina: nos processos interacionais em eventos de Oralidade e de Letramento (projeto PRÓ-VARIAÇÃO). O

Ano de formação: 2007 objetivo foi o de identificar, descrever e analisar a variação linguística na língua falada e na língua escrita de usuários do português, seja em atividades de oralidade, seja em atividades de letramento; caracterizar a variação linguística na comunidade social e linguística de Teresina e do Piauí, discutir a variação linguística com professores de língua e com a comunidade teresinense e piauiense, para conscientizá-los da sua importância no processo de comunicação e interação social. Iniciou-se também um novo projeto de pesquisa: Variação Linguística em Teresina nos eventos de Oralidade e de Letramento: pesquisa e teorização.

da Costa

O objetivo do projeto é constituir um banco de dados anotado que seja representativo da língua portuguesa em Juiz de Fora no século XIX. Com base nos documentos organizados e disponibilizados pelo Arquivo Histórico da Prefeitura de Juiz de Fora, o grupo pretende selecionar para a pesquisa os tipos específicos de documentação que permitam aferir como a língua portuguesa era efetivamente falada no período. Desse modo, como não há dados reais de fala que representem o uso da língua no século XIX, recorrer-se-á a textos escritos que, por sua própria natureza, tragam claramente marcas de oralidade e permitam, assim, atestar o vernáculo.

Instituição: Universidade Federal de Juiz de 


\section{8 - Constituição, variação e mudança do/no português}

Ano de formação: 2008

Líderes: Eliana Sandra Pitombo Teixeira e Norma Lucia Fernandes de Almeida

Instituição: Universidade Estadual de Feira de Santana - UEFS

\section{9 - VARFON-Minas}

Ano de formação: 2008

Líder: Maria do Carmo Viegas

Instituição: Universidade Federal de Minas Gerais - UFMG

\section{0 - NEPLAE - Núcleo de Estudos e \\ Pesquisas em Linguística Aplicada à \\ Educação}

Ano de formação: 2008

Líderes: Valteir Martins e Silvana de Andrade Martins

Instituição: Universidade do Estado do Amazonas - UEA
O grupo vem desenvolvendo trabalhos de acordo com sua agenda de pesquisa, que compreende os seguintes aspectos: 1) formação de corpora diacrônicos e sincrônicos que buscam abranger as populações que estiveram na base da formação do português brasileiro especificamente em área baiana, a saber: corpora escritos por população culta, semi culta popular escritos por populações de origem portuguesa, indígena e africana e corpus do português africano. 2) controle de produção dos corpora; 3) estudos linguísticos; 4) estudos comparativos do português brasileiro/português angolano/português europeu. $\mathrm{O}$ grupo possui os seguintes projetos: Para a história do português brasileiro (PHPB-BAHIA/EQUIPE-UEFS); Em busca das raízes do português brasileiro: Bahia-Angola; A língua portuguesa no semi-árido baiano (fase 3); O futuro da escrita baiana; A concordância verbal em Feira de Santana: alguns elementos para a caracterização do português do Brasil.

Os objetivos do grupo são: 1) Contribuir para a documentação e constituição de um banco de dados relativo aos dialetos mineiros, tendo em vista sistematizar/digitalizar a documentação a respeito desses dialetos; 2) Descrever e analisar seus aspectos fonéticos, fonológicos, morfológicos e lexicais; 3) Descrever e analisar seus aspectos sociolinguísticos e da formação sócio-histórica; 4) Contribuir para a formação de profissionais qualificados para atuar nas linhas de variação e mudança, sociolinguística, dialetologia e linguística histórica, assim como em teoria e análise linguística; 5) Discutir variação inter- e intradialetal; 6) Discutir mudança linguística; 7) Discutir tipologicamente variação/mudança linguística.

Este projeto propõe a instauração de pesquisas sistemáticas sobre a variedade urbana culta da língua portuguesa falada na cidade de Manaus. As pesquisas, desenvolvidas na perspectiva teórica da sociolinguística variacionista laboviana e norteadas pelos critérios teóricometodológicos empregados pelos NURCs, pretendem documentar as especificidades da fala culta dos manauaras, constituindo um banco de dados digitalizados, incluindo documentação sonora. Esse projeto comporta três subprojetos: a documentação de elocuções formais (EF), os registros da situação de fala dialógica entre dois informantes (D2) e os diálogos entre documentador e informante (DID). 0 material de estudo produzido servirá de subsídios para proposição de pesquisas posteriores sobre essa variedade culta da língua portuguesa, nas áreas de fonética/fonologia, morfossintaxe, léxico, entre outras.

O VALCO surgiu da ideia de se desenvolver um projeto que estivesse alinhado com a tradição de outros núcleos de pesquisa sociolinguística no Brasil, como o VALPB, na Paraíba, e o VARSUL, na região sul, no sentido de se criar um banco de dados linguísticos da região centrooeste. Nos últimos dez anos, têm se desenvolvido, no âmbito da pesquisa sociolinguística realizada na Universidade de Brasília, pesquisas em nível de mestrado e doutorado que elegeram como objeto de estudo variedades linguísticas desta região, o que possibilitou a constituição de corpora de seus diversos falares. O projeto VALCO é fruto dessa iniciativa, que reuniu um grupo de professores e estudantes de pós-graduação da Universidade de Brasília ligados à área de pesquisa da Sociolinguística Variacionista com o objetivo de inicialmente: (i) identificar, documentar e caracterizar uma variedade linguística própria do Distrito Federal, dentro do cenário linguístico nacional; (ii) organizar um banco de dados on-line de amostras de língua falada já coletadas por pesquisadores envolvidos em projetos de pesquisa sociolinguística, envolvendo, além da UnB, as universidades de Goiás, Mato Grosso e Mato Grosso do Sul. Segundo os pesquisadores, o fundamento do VALCO é reunir e socializar o conhecimento e a pesquisa linguística que vem sendo desenvolvida no âmbito da variação linguística, disponibilizando material de fala coletado por meio de entrevistas labovianas típicas para todos os profissionais que atuem no ensino de língua portuguesa, em nível fundamental médio ou superior, uma vez que, em geral, esse conhecimento permanece restrito ao ambiente acadêmico. $O$ projeto é apoiado pela FAPDF e pela UnB.

Em outubro de 2008, ocorreu um primeiro encontro de jovens pesquisadores, orientados pela profa. Marta Scherre, denominado de I GEAS, a respeito de pesquisas em andamento na área de Sociolinguística, contando com a presença de vários professores do LIP/UnB, profa. Heloísa Salles, profa. Rachel Dettoni, profa. Cibele Brandão e prof. Marcos Bagno, da área de Sociolinguística. Neste dia também foi apresentada a tradução do clássico livro Padrões Sociolinguísticos, de William Labov, da qual participaram Marcos Bagno, Marta Scherre Caroline Cardoso. A partir desse primeiro evento, deu-se continuidade aos encontros como forma de divulgação das pesquisas que estão sendo realizadas na área de Sociolinguística na UnB, com palestras, comunicações e, também, um minicurso sobre o Goldvarb X, a mais nova versão do programa de tratamento estatístico de dados linguísticos variáveis.

0 projeto visa elaborar um quadro descritivo de fenômenos linguísticos (fonético-fonológicos, morfológicos, sintáticos semânticos, pragmáticos) identificados como possíveis elementos que estão (ou estavam) em variação no português ou em outras línguas naturais (como, por exemplo, espanhol) e que ainda não foram avaliados do ponto de vista sincrônico e/ou diacrônico. Para isso, os textos analisados - orais ou escritos - são organizados em um banco de dados, composto por gravações de entrevistas (posteriormente transcritas), de jornais manuscritos, documentos etc. As informações obtidas pela análise de dados (extraídos do corpus) são tratadas estatisticamente, seguindo a metodologia da sociolinguística laboviana e em seguida, analisadas qualitativamente. Segundo os pesquisadores, esse projeto busca: (i) contribuir para o levantamento de características do português, e, consequentemente, para a construção da história do português brasileiro; (ii) possibilitar a realização de estudos comparativos entre o português e outras línguas, como por exemplo, o espanhol e o português. O Grupo de Pesquisas Sociolinguísticas (SOCIOLIN-CE) atua no Estado do Ceará e visa ao desenvolvimento de pesquisas sobre: a) variação linguística e mudança linguística, com base na Teoria da Variação e Mudança ou Sociolinguística Quantitativa; b) ensino de língua materna e estrangeira, na perspectiva da Sociolinguística Aplicada; e c) descrição e análise linguísticas, a partir da correlação entre Sociolinguística e Funcionalismo, pelo viés Sociofuncionalista. O grupo busca analisar variação linguística e mudança em tempo real e em tempo aparente, nos níveis fonético-fonológico, morfossintático, lexical, sintático-semântico e pragmático-discursivo, a partir de corpora orais e escritos. Objetiva, também, disponibilizar aos pesquisadores corpora

Instituição: Universidade Federal do Ceará UFC 


\section{5 - Amostra digital VARSUL}

Ano de formação: 2009

Líder: Izete Lehmkuhl Coelho

Instituição: Universidade Federal de Santa Catarina - UFSC

\section{6 - PHPB-SC}

Ano de formação: 2009

Líder: Izete Lehmkuhl Coelho

Instituição: Universidade Federal de Santa Catarina - UFSC

\section{7 - A variação e deriva da língua,} estudadas a partir de textos arcaicos

Ano de formação: 2010

Líder: Ângela Tonelli Vaz Leão

Instituição: Pontifícia Universidade Católica de Minas Gerais - PUC Minas

38 - Descrição e análise linguística

Ano de formação: 2010

Líderes: Ailma do Nascimento Silva e

Lucirene da Silva Carvalho

Instituição: Universidade Estadual do Piauí UESPI

39 - Atlas Linguístico do Brasil - Região Sul

Ano de formação: 2010

Líder: Felício Wessling Margotti

Instituição: Universidade Federal de Santa Catarina - UFSC

\section{0 - ESAELP}

Ano de formação: 2010

Líder: Angela Marina Bravin dos Santos

Instituição: Universidade Federal Rural do Rio de Janeiro - UFRRJ

\section{1 - Estudos Diacrônicos e Sincrônicos do Português Falado no Amazonas}

Ano de formação: 2010

Líder: Maria Sandra Campos

Instituição: Universidade Federal do Amazonas - UFAM

42 - Grupo de Estudos em Teoria da Gramática (GETEGRA)

Ano de formação: 2010

Líderes: Marcelo Amorim Sibaldo e Adeilson Pinheiro Sedrin organizados pelo método de pesquisa sociolinguística, que possam contribuir para o estudo de variáveis linguísticas e possibilitar o entendimento das diferenças linguísticas condicionadas por diferentes espaços geográficos, comunidades, classes sociais, faixas etárias, níveis de formalidade, conduzindo à valorização da pluralidade sociocultural e a uma postura respeitosa no trato das diferenças sociolinguísticas.

Este projeto, numa parceria interinstitucional que reúne a UFSC, a PUCRS, a UFRGS e a UFPR, tem por objetivo central disponibilizar à comunidade científica nacional e internacional uma amostra digital de fala (i) do projeto VARSUL (Variação Linguística Urbana na Região Sul) referente às três capitais do sul do Brasil (Curitiba, Florianópolis e Porto Alegre); e (ii) dos bancos de dados de fala rural de Florianópolis, a fim de servir como fonte de informação sobre a(s) variedade(s) sociolinguística(s) do sul do país e como fonte para a pesquisa sociocultura dos informantes. Segundo os pesquisadores, a disponibilização deste banco virtual poderá fornecer o desenvolvimento de projetos voltados para a pesquisa, o ensino e a extensão, tanto nos cursos de pós-graduação quanto nos de graduação, nas modalidades presenciais e a distância; bem como oferecer aos interessados em geral uma fonte de dados linguísticos reais. O Projeto "Para a história do português brasileiro de Santa Catarina" (PHPB-SC), desenvolvido por pesquisadores da UFSC, integra-se à proposta do "Projeto Nacional Para a história do português brasileiro", criado em abril de 1997 pelo Programa de Pós-Graduação em Filologia e Língua Portuguesa da Universidade de São Paulo (USP), o qual conta desde então com a participação de pesquisadores de diferentes regiões e de diferentes instituições brasileiras. Segundo os pesquisadores, o PHPB-SC tem como propósito descrever a realidade linguística do português de Santa Catarina dos últimos três séculos, enquadrando-se na metodologia de trabalho do projeto coletivo, de levantamento de fontes específicas e representativas, fontes estas oriundas de levantamentos exaustivos em arquivos históricos, abarcando estudos descritivos de variação e/ou mudança linguísticos nos diferentes níveis gramaticais do português falado e escrito, bem como de situações de contato linguístico, com diferentes abordagens: geolinguística e sociolinguística, numa perspectiva formal e funcional.

O grupo objetiva estudar a variação e da mudança linguística como características inerentes às línguas naturais bem como sua correlação com fatores de natureza estrutural e não estrutural. Através da leitura e análise de textos arcaicos, são estudadas formas do léxico e da morfossintaxe que atestem a variação linguística, suas tendências e a mudança daí resultante, na evolução da língua portuguesa.

Este grupo de estudo, vinculado ao Núcleo de Pesquisas e Estudos Linguísticos (NUCEL), tem o propósito de investigar, baseados nos pressupostos teórico-metodológicos da Sociolinguística de orientação laboviana, fenômenos linguísticos variáveis em dados de fala e escrita do estado do Piauí.

Este grupo abarca estudos descritivos de variação e/ou mudança linguística nos diferentes níveis gramaticais do português falado (Bancos de Dados VARSUL, ALERS, ALIB) e escrito (peças teatrais, cartas, produções textuais de alunos), bem como de situações de contato linguístico, com diferentes abordagens: geolinguística e sociolinguística, numa perspectiva formal e funcional.

O ESAELP agrega pesquisadores que investigam fenômenos sintáticos em três variedades do português: brasileira, europeia e moçambicana, seja na fala ou na escrita, utilizando, para tanto o arcabouço teórico-metodológico da Sociolinguística Variacionista associado, por um lado, à teoria linguística de Princípios e Parâmetros, de base gerativa, por outro, ao Funcionalismo Linguístico, estabelecendo um intercâmbio com os estudos desenvolvidos no âmbito da UFRJ sob orientação de Duarte, no que tange aos estudos gerativistas, e de Paiva, em relação aos trabalhos funcionalistas. O objetivo principal é reunir os resultados de pesquisas já concluídas e das que serão desenvolvidas na UFRRJ para produzir textos que possam servir de apoio para o ensino de língua portuguesa nos níveis fundamental e médio, o que permite ao grupo contar com duas linhas de pesquisas: a) Variação, morfossintaxe e ensino; b) Variação, Funcionalismo e ensino.

O Grupo de Pesquisa se propõe a realizar uma investigação multidisciplinar, no âmbito social, histórico e linguístico descritivo, a fim de descrever, diacrônica e sincronicamente, os fatos da língua portuguesa na fala, especificamente, do homem amazônida. Neste sentido, os estudos serão focados em vários níveis da língua: descrever e analisar os aspectos fonéticos e fonológicos, bem como as vogais anteriores e posteriores tônicas, as vogais nasalizadas, além de caracterizar os elementos identificadores de marcas dialetais, ocasionados pela prosódia descrever e analisar os aspectos sociolinguísticos da fala em destaque quer seja no nível lexical, no nível sintático, no nível do discurso. Pretende-se também contribuir para o avanço desta linha de pesquisa no Amazonas, envolvendo professores-alunos, pesquisadores da área de Letras.

Este grupo busca realizar estudos de questões teóricas essenciais colocadas pelo programa de investigação da gramática gerativa tanto no seu modelo de Princípios \& Parâmetros (CHOMSKY, 1981 e 1986) quanto no seu quadro minimalista (CHOSMKY, 2000 e sequência) em interface com estudos sobre a relação entre língua e sociedade pelo viés da teoria da variação e mudança linguística laboviana (LABOV, 1972 e 1994), explorando tanto a sua metodologia quanto os seus pressupostos e aplicando-os aos dados do português brasileiro e 
Instituição: Universidade Federal Rural de

de outras línguas, quando se fizer necessário.

Pernambuco - UFRPE

43 - Linguagem e Contexto Social

Ano de formação: 2010

Este grupo abarca estudos de fenômenos estáveis ou em variação e/ou mudança linguística das comunidades monolíngues e bilíngues da Mesorregião Grande Fronteira do MERCOSUL e

Líderes: Marcelo Jacó Krug e Cristiane Horst arespectiva sincrônica e diacrônica, para comparação dos resultados entre as

Instituição: Universidade Federal da Fronteira Sul - UFFS

\section{4 - PORTVIX: uma perspectiva} sociolinguística sobre a fala de Vitória

Ano de formação: 2010 variedades faladas e escritas da região sul e entre outras regiões brasileiras.

Líder: Lilian Coutinho Yacovenco

Durante 2001 e 2002, foram gravadas quarenta e seis entrevistas com informantes nascidos em Vitória, divididos segundo as variáveis relativas ao gênero do informante, à sua idade e à sua escolaridade. O presente grupo de pesquisa objetiva discutir, à luz da perspectiva variacionista (Labov, 1972), a existência ou não de marcas na fala capixaba e também mostrar como a variedade capixaba se apresenta diante de outras variedades brasileiras. Para tanto, analisam fenômenos morfossintáticos e sintáticos, como a concordância nominal, a variação nós/a gente, a variação você/cê e a ausência/presença de artigo definido diante de antropônimos e possessivos, o preenchimento do objeto direto anafórico, a expansão dos usos do gerúndio e a variação subjuntivo/indicativo.

Santo - UFES

O grupo é constituído de professores da PUCRS e de Universidades Federais do Rio Grande do Sul: UFRGS, UFPEL e FURG. Todos os membros são doutores na área e estão em atividade nas respectivas Universidades. Aspectos IV, diferente dos demais que o precederam, detêm-se na fala do Rio Grande do Sul, distinguindo-a por suas propriedades fonológicas como uma das variedades do português brasileiro, que figura ao lado de outras: carioca, paulista, nordestina, etc. A intenção é adaptar a uma linguagem acessivel ao grande público os resultados de análises realizadas e discutidas nos subprojetos precedentes que levam o título geral "Aspectos da Fonologia do Português Brasileiro". Os pontos relevantes a serem considerados são os seguintes: a) uso maior ou menor de regras fonológicas do sistema b) resistência (ou não) a regras novas $\mathrm{c}$ ) variáveis específicas do dialeto d) aspectos inovadores. Objetiva-se a produção de um livro, sem formalismo teórico, mas com preservação da informação linguística, que ofereça leitura de grande alcance sobre os seguintes temas: 1- a vibrante e suas variantes 2palatalização variável da oclusiva alveolar 3- variação da lateral 4- monotongação do ditongo nasal 5- inserção do glide em sílaba final 6- variação da pretônica.

\begin{tabular}{ll}
\hline 46 - Grupo ALAP & O grupo objetiva evidenciar as variedades da língua portuguesa faladas no Amapá, a partir dos \\
& critérios de idade, escolarização e sexo, detectando as possíveis variáveis de sexo, idade e \\
escolaridade que podem vir a influenciar os diferentes usos na comunidade. 0 grupo pretende \\
realizar a descrição do falar amapaense por meio da elaboração do atlas linguístico do Amapá.
\end{tabular}

Instituição: Universidade Federal do Amapá UNIFAP

47 - Tradução e Sociolinguística

Variacionista: a busca de interfaces na

análise do processo tradutório

Ano de formação: 2010

As pesquisas realizadas pelo grupo têm como objetivo discutir o processo tradutório e, em especial, a noção de equivalência a partir dos pressupostos teóricos da Sociolinguística Variacionista (LABOV, 1972, 1982, 1994, 2001). Partindo do princípio de que os dialetos e os socioletos que compõem cada sociedade/comunidade linguística são representativos de realidades específicas, pretende-se debater qual seria o papel do tradutor como intermediador

Líder: Patrícia Fabiane Amaral da Cunha Lacerda de variantes e variedades linguísticas motivadas socialmente.

Instituição: Universidade Federal de Juiz de Fora - UFJF

O Grupo de Pesquisa em Fonologia surgiu com a intenção de desenvolver um banco de dados em fonologia, no que diz respeito à aquisição, à variação e aos desvios. Esse banco pode servir como base para futuros artigos e trabalhos de monografia, dissertações e teses. A ideia é desenvolver descrições e análises de dados do dialeto nordestino, visto que há poucos bancos de dados e poucas descrições acerca desse dialeto, especialmente no que se refere aos padrões de aquisição fonológica e à investigação da variação na aquisição. 0 grupo também tem como objetivo desenvolver pesquisas nas áreas da fonologia clínica, aquisição e variação fonológica, desvios fonéticos e fonológicos e modelos teóricos. Tem como objetivos específicos: criar um banco de dados de aquisição fonológica; promover discussões e análises que possam contribuir a áreas afins, como a de educação e à terapia fonoaudiológica; criar um espaço de debates, leituras conjuntas, discussões e análises acerca da fonologia do PB, em relação aos diversos modelos teóricos e entraves metodológicos; estudar o processo de aquisição de outros sistemas fonológicos (aquisição de L2), pelos falantes paraibanos; disponibilizar os resultados das pesquisas através de publicação de artigos em periódicos, apresentação de trabalhos em congressos, publicação de livros, dentre outros. Áreas de pesquisa: a) pesquisa teórica: avaliação e comparação de modelos fonológicos e sua aplicabilidade à descrição do componente fonológico de línguas naturais, esclarecendo suas vantagens, falhas e limitações b) pesquisas aplicadas ao PB, voltadas às especificidades dialetais; c) pesquisas aplicadas em: alfabetização, fonoaudiologia (fonologia clínica), línguas indígenas, línguas de sinais, L2, linguística e informática e linguística forense.

Como se pode observar, há um número significativo de grupos que pesquisam a língua (gem) por meio dos pressupostos da teoria da variação e mudança, muitas vezes alinhadas a outras teorias, como o funcionalismo e o gerativismo. Há ainda grupos interdisciplinares que aliam a sociolinguística variacionista às teorias da tradução e aos estudos de fonologia clínica e aquisição de linguagem, como é o caso dos dois 
últimos grupos. É interessante notar que muitos grupos buscam também uma interface entre a sociolinguística e a educação. Alguns grupos contam com apoio de agências de fomento à pesquisa de programas governamentais nacionais e internacionais (CNPq, FINEP, FAPESP, FAPERGS, FAPEMIG, FAPESB, FAPDF, Fullbright/CAPES, PIBIC). Em relação à distribuição, uma grande parte dos grupos se situa na região Sudeste, com 19 grupos, e na região Sul, com 10 grupos; nas regiões Norte e Nordeste foram localizados 9 e 8 grupos, respectivamente; e na região Centro-Oeste, foram encontrados 2 grupos de pesquisa e uma nova associação científica de estudos da linguagem. ${ }^{3}$

Na região Sudeste, em especial o estado do Rio de Janeiro, um pioneiro em estudos sobre a variação e mudança linguística com o projeto Censo na UFRJ, encontramos no levantamento o GIEL (grupo 6), grupo interinstitucional formado pelas universidades UFF, UFRJ, PUC-Rio, UFJF, liderado por Maria Jussara Abraçado de Almeida e Monica Maria Guimarães Savedra, constituindo-se de uma grande rede de pesquisadores voltados para questões relacionadas ao uso da língua. Há também o grupo "Para uma História do Português Brasileiro: 500 anos de Língua Portuguesa” (grupo 11), liderado por Dinah Callou e Afranio Barbosa, cuja equipe tem suas raízes no projeto NURC-Rio, e por meio da articulação de vários projetos pessoais e coletivos investiga questões histórico-linguísticas envolvidas na formação do português brasileiro. Percebe-se que os grupos mais antigos passam agora a constituir grandes aglomerados em forma de redes de pesquisa, o que permite a expansão da base de dados e maior fluxo de informação entre pesquisadores de diferentes instituições. Mais recentemente também, formado no ano de 2010, está o grupo ESAELP (grupo 40), situado na Universidade Federal Rural do Rio de Janeiro, que busca investigar fenômenos sintáticos em três variedades do português (brasileira, europeia e moçambicana) por meio de interface com as teorias de base gerativa e de base funcionalista. O estado de Minas Gerais, com doze grupos de pesquisa (grupos 3, 5, 7, 8, 17, 18, 20, 27, 29, 33, 37, 47), tem se mostrado um celeiro para estudos voltados à documentação e constituição de um banco de dados relativo aos dialetos mineiros e à história do português brasileiro. Os grupos, distribuídos nas seguintes universidades: UFMG, PUC-Minas, UFO, UFJF e UFTM, buscam descrever e analisar os aspectos fonéticos, fonológicos, morfológicos e lexicais e discutir a variação e mudança linguística em projetos muitas vezes interdisciplinares, como é o caso dos grupos que trabalham em conjunto com os estudos literários (grupos 5 e 7), linguística dos gêneros e tipos textuais (grupo 18) e estudos da tradução (grupo 47). No estado de São Paulo, dando continuidade ao projeto de estudo da "norma linguística urbana culta"4, encontra-se o NURC-núcleo USP (grupo 14), liderado por Dino Preti, investigando aspectos organizacionais, estruturais e linguísticos da língua falada, ou da norma linguística urbana culta praticada pelos usuários da cidade de São Paulo, por meio da modalidade oral, ou da escrita na interface com a oralidade. Há ainda dois outros grupos que investigam as variedades usadas no interior do estado. O Grupo de Estudos em Linguística Histórica (grupo 9), liderado por Rosane Berlinck e Clotilde Murakawa, estuda a variação e mudança em relação à morfologia e sintaxe, estudando tempo aparente e tempo real, por meio de amostras de fala individuais da região central do estado de São Paulo (Araraquara, São Carlos e Itirapina). O projeto ALIP (grupo 13), liderado por Sebastião Carlos Gonçalves e Luciani Tenani, possui um banco de dados denominado Iboruna, com amostras de fala, sistematicamente controladas por variáveis sociais, provenientes de cidades do noroeste do estado de São Paulo, na região de São José do Rio Preto (Bady Bassit, Cedral, Guapiaçu, Ipiguá, Mirassol, Onda Verde), buscando descrever o português do interior paulista. No Espírito Santo, encontramos o grupo PortVix (grupo 44), liderado por Lilian Coutinho Yacovenco, que se propõe a investigar, sob a perspectiva da Sociolinguística Variacionista, a fala capixaba. O grupo afirma que a identidade linguística do capixaba não é fenômeno sobre o qual se tenha grande conhecimento, e que traços característicos dessa identidade não são imediatamente nítidos para quem visita Vitória, nem para os

3 Esta última não consta na tabela do levantamento, por se constituir como uma associação científica de estudos da linguagem nos moldes de associações criadas anteriormente em outras regiões do país para intercâmbio entre pesquisadores, como a ABRALIN, a ANPOLL, o GEL, o GELNE, entre outras, mas fará parte de nossa discussão no artigo.

4 O Projeto NURC, iniciado em 1969, tinha inicialmente o objetivo de documentar e descrever o português culto falado em cinco capitais brasileiras: São Paulo, Rio de Janeiro, Porto Alegre, Salvador e Recife. Na década de 80, considerando as novas tendências de análise linguística, o escopo do projeto foi ampliado, incorporando análise da conversação, análise da narrativa, análise sócio-pragmática do discurso e outros. 
próprios capixabas. Se indagados a respeito desta questão, até mesmo os próprios capixabas afirmam que falam uma variedade não marcada e, caso se desloque para outros estados, não são linguisticamente identificados. Para o grupo, muitas são as razões para tal desconhecimento, entre as quais está a ausência da descrição da variedade falada em Vitória, que busca, então, suprir tal lacuna na descrição do português falado no Brasil.

Na região Sul, os grupos de pesquisa liderada por Odete Menon (grupo 22), Leda Bisol (grupo 45), Izete Coelho (grupo 35) dão continuidade ao projeto VARSUL (Variação Linguística Urbana da Região Sul do Brasil, implementado pelas universidades UFRGS, UFPR, UFSC e PUC/RS, desenvolvendo pesquisas linguísticas centradas na descrição do português falado no sul do país, levando em conta as diferentes áreas da análise linguística: fonologia, morfologia, sintaxe, léxico, semântica e discurso. O projeto constitui-se de: Banco de Dados VARSUL, Amostra Digital VARSUL e Banco de Dados Diacrônico. Há também grupos de pesquisa ligados à composição de um atlas linguístico etnográfico da região sul, como é o caso do ALERS, liderado por Cléo Altenhofen e José Luiz da Veiga Mercer, no Rio Grande do Sul, e por Felício Margotti, em Santa Catarina, para a comparação de áreas em esfera interestadual. Mais recentemente, em 2010, Felício Margotti também constituiu o grupo Atlas Linguístico do Brasil - Região Sul (grupo 39), abarcando estudos descritivos de variação e/ou mudança linguística nos diferentes níveis gramaticais do português falado (Bancos de Dados VARSUL, ALERS, ALIB) e escrito (peças teatrais, cartas, produções textuais de alunos), bem como de situações de contato linguístico, com diferentes abordagens: geolinguística e sociolinguística, numa perspectiva formal e funcional. O grupo de Luís Isaías Amaral e Maria José Bladskovski Vieira (grupo 1), da Universidade Federal de Pelotas, também estuda o português da região sul do Brasil, mais especificamente do extremo sul, em relação à variação e mudança nos níveis de fonologia, morfologia e sintaxe, enquanto que o grupo de Marcelo Krug e Cristiane Horst (grupo 43) investiga a variação e mudança na fala de comunidades monolíngues e bilíngues nas regiões de fronteira com os países do MERCOSUL. De fato, a localização próxima às fronteiras com outros países, assim como a colonização europeia nestas regiões influencia fortemente os estudos, como no caso do grupo liderado por Andréa Tamanine e Maria da Graça Albino de Oliveira (grupo 11), que busca contribuir com a gramática do português brasileiro falado, especialmente no âmbito dos pronomes pessoais e do bilinguismo português/alemão em Santa Catarina.

Na região Nordeste, encontramos dois grupos que buscam constituir um panorama sociolinguístico do português popular do Estado da Bahia. O projeto Vertentes (grupo 4), liderado por Dante Lucchesi Ramacciotti, da UFBA, busca constituir acervos de fala das diversas variedades da língua popular do interior do estado da Bahia e de sua capital, e estudar os processos de variação e mudança induzidos pelo contato entre línguas, assim como os processos de nivelamento a partir dos grandes centros urbanos. O "Projeto Constituição, variação e mudança do/no português", liderado por Eliana Sandra Pitombo Teixeira e Norma Fernandes de Almeida (grupo 28), da Universidade Estadual de Feira de Santana, tem sua agenda de pesquisa voltada para a formação de corpora diacrônicos e sincrônicos que buscam abranger as populações que estiveram na base da formação do português brasileiro, de origem portuguesa, indígena e africana, e corpus do português africano. O grupo possui 5 projetos de pesquisa, dentro os quais estudam a história do português brasileiro (PHPB-BAHIA/EQUIPE-UEFS), o contato entre línguas, no caso com o português de Angola, e a mudança no nível sintático na região de Feira de Santana. Foram encontrados também 2 grupos de pesquisa no estado do Piauí, o grupo Descrição e Análise Linguística (grupo 38), liderado por Ailma do Nascimento Silva e Lucirene da Silva Carvalho, e o grupo LES (grupo 26), liderado por Catarina Mendes da Costa, que buscam de descrever e analisar a variação linguística em Teresina. No Sergipe, o GELINS, liderado por Raquel Meister Ko Freitag e Leilane Ramos da Silva (grupo 23), busca investigar os fenômenos da linguagem no agreste central sergipano, combinando os pressupostos teóricometodológicos da Sociolinguística Variacionista e do Funcionalismo Linguístico de orientação norteamericana para a análise de processos de variação e mudança linguística em nível gramatical. No Ceará, o Núcleo de Estudos Linguísticos do Cariri (grupo 19), liderado por Sandra Espínola Almeida e Thiago Alves, busca descrever o perfil linguístico do falante caririense e estudar, sincrônica e diacronicamente, 
fenômenos relacionados ao português, como a relação fala/escrita, oralidade/letramento, variação e mudança linguística; enquanto que o SOCIOLIN-CE (grupo 34), liderado por Márluce Coan, da Universidade Federal do Ceará, também desenvolve descrição e análise linguística a partir da correlação entre a Sociolinguística e o Funcionalismo, buscando também aliar a pesquisa ao ensino e aprendizagem de língua materna e estrangeira, na perspectiva da Sociolinguística Aplicada. Em Pernambuco, o GETEGRA (grupo 42), liderado por Marcelo Sibaldo e Adeilson Sedrins, busca alinhar a investigação da gramática gerativa a pressupostos da teoria da sociolinguística laboviana para o estudo do português brasileiro. Na Paraíba, o Grupo de estudos em fonologia (grupo 48), liderado por Aba Carla Vogeley e Demerval da Hora Oliveira $^{5}$, pretende desenvolver descrições e análises do dialeto nordestino. O grupo visa construir um banco de dados em fonologia, para o desenvolvimento de pesquisas nas áreas da fonologia clínica, aquisição e variação fonológica, desvios fonéticos e fonológicos e modelos teóricos.

Na região Norte, o Observatório de Linguagem do Sul e Sudeste do Pará (grupo 15), liderado por Eliane Pereira Machado Soares, da UFPA, objetiva a identificação, análise e mapeamento da variação linguística (variação fonética, morfossintática e lexical) na Mesorregião Metropolitana de Belém e do Nordeste Paraense. Também no estado do Pará, encontramos o projeto Vozes da Amazônia (grupo 12), que tem como objetivo verificar a concorrência de variantes no falar interiorano da Amazônia paraense, tendo implantado o primeiro laboratório de ciência e tecnologia da fala da região norte. A fala amazonense também é estudada em uma perspectiva da teoria da variação no estado do Amazonas por dois grupos de pesquisa: o NEPLAE (grupo 30), liderado Valteir Martins e Silvana de Andrade Martins, da Universidade do Estado do Amazonas, pautando-se nos critérios teórico-metodológicos empregados pelos NURCs para documentar as especificidades da fala culta dos manauaras e propor pesquisas sobre essa variedade culta da língua portuguesa, nas áreas de fonética/fonologia, morfossintaxe e léxica; e o grupo Estudos Diacrônicos e Sincrônicos do Português Falado no Amazonas (grupo 41), liderado por Maria Sandra Campos, que visa descrever, diacrônica e sincronicamente, os fatos da língua portuguesa na fala, especificamente, da população amazônida, por meio de estudos focados em aspectos fonéticos e fonológicos, elementos identificadores de marcas dialetais, ocasionados pela prosódia, e aspectos sociolinguísticos da fala no nível lexical, nível sintático e do discurso. Em Rondônia, o GEPS (grupo 21), liderado por Maria do Socorro Pessoa e Fábio Santos de Andrade, também pesquisa as atitudes linguísticas das comunidades amazônidas em relação à enorme variação dialetal da língua portuguesa existente, em contato com outras línguas e dialetos na região. Em Tocantins, o Núcleo de Estudos da Linguagem (grupo 16), liderado por Jaciara Rondon Gonçalves e Juscéia Aparecida Veiga Garbelini, visa investigar 8 comunidades quilombolas das 15 reconhecidas pelo Estado de Tocatins, por meio de mapeamento sociolinguístico e estudos das variações sociais. No Acre, o Grupo de Estudos Linguísticos do Acre (grupo 25), liderado por Vicente Cruz Cerqueira e Paula Tatianne Carréra Szundy, objetiva descrever e analisar o português brasileiro, com enfoque especialmente no ecossistema linguístico do Acre, considerando sua história interna e externa, buscando também uma interface com a educação. No Amapá, o Grupo ALAP (grupo 46), visa investigar as variedades da língua portuguesa faladas no Amapá, a partir dos critérios de idade, escolarização e sexo, detectando as possíveis variáveis de sexo, idade e escolaridade que podem vir a influenciar os diferentes usos na comunidade.

Na região Centro-Oeste, destacam-se os grupos de pesquisa VALCO (grupo 31) e GEAS (grupo 32), em iniciativas que visam congregar pesquisadores de diferentes universidades da região com o intuito de investigar a situação linguística da região. O VALCO tem como uma das metas centrais a organização de corpora da região centro-oeste, à semelhança de iniciativas nas regiões Sudeste (PEUL-RJ; PORTVIX-ES),

\footnotetext{
5 Demerval da Hora é também líder do VALPB, criado em 1993, grupo que têm contribuído para que se estabeleça um perfil linguístico do falante de João Pessoa e uma melhor compreensão dos fenômenos envolvidos na Língua Portuguesa como um todo por meio de estudos voltados para aspectos diacrônicos a partir de textos manuscritos e para as relações entre fala/escrita e fala/leitura.
} 
Sul (VARSUL) e Nordeste (VALPB; PORCUFORT ${ }^{6}$ ), buscando reunir e socializar o conhecimento e a pesquisa linguística que vem sendo desenvolvida no âmbito da variação linguística, disponibilizando material de fala coletado por meio de entrevistas labovianas típicas para todos os profissionais que atuem no ensino de língua portuguesa, em nível fundamental, médio ou superior, contribuindo para que esse conhecimento não permaneça restrito ao ambiente acadêmico. O GEAS é um grupo de estudos de alunos do Programa de Pós-graduação em Linguística da UnB, cujo foco é a congregação entre os estudos de linguagem, sociedade e ensino de língua portuguesa, fomentando a troca de experiência entre pesquisadores de diversas regiões e de diversas instituições.

Há ainda que se mencionar uma nova associação científica de estudos da linguagem criada em outubro de 2000, o GELCO (Grupo de Estudos da Linguagem do Centro-Oeste), congregando profissionais (pesquisadores e professores) que atuam nas áreas de Linguística, Línguas e Literaturas na região centrooeste do Brasil. Como entidade regional, o GELCO conta com uma rede de associados que se estende desde Mato Grosso do Sul e Mato Grosso, até Goiás e o Distrito Federal, incluindo o estado de Tocantins, o qual, hoje integra o norte do Brasil, ainda que, como colocado pelos membros do grupo, culturalmente continue sendo parte da região centro-oeste. O grupo tem buscado abrir um espaço político para o fomento e a expansão da pesquisa linguística no centro-oeste, abrindo espaços para a troca de conhecimentos e de procedimentos teórico-metodológicos dentro de linhas de pesquisa cujos projetos contemplem a variação sincrônica e diacrônica, bem como a mudança linguística. No eixo sincrônico, os centros de ensino e pesquisa do centro-oeste desenvolvem pesquisas regionais, baseadas nos pressupostos teóricometodológicos da Sociolinguística e da Dialetologia. Segundo informações encontradas no site oficial do grupo (http://www.gelco.org.br/web/), em Mato Grosso do Sul, por exemplo, estão sendo desenvolvidos estudos linguísticos voltados para variantes determinadas geograficamente e para o bilinguismo, considerando-se a influência do espanhol e das línguas indígenas, bem como as influências decorrentes do processo migratório.

Nosso levantamento não pretende ser exaustivo, mesmo porque a extensão do território brasileiro constitui uma das dificuldades em se realizar um mapeamento de todos os grupos atuantes nele. ${ }^{7}$ Outros trabalhos podem estar sendo desenvolvidos coletiva ou isoladamente em diferentes regiões do país ${ }^{8}$, porém a nosso ver, a formação de grupos de pesquisa é um importante passo a ser dado pelos pesquisadores em nosso país para que redes de pesquisa e banco de dados que recubram diversas áreas geodialetais do território brasileiro possam estimular, como colocado por Mollica e Roncarati (2001), o estudo regular e sistemático de uma produção comparativa em relação a questões teóricas de encaixamento e implementação da mudança e sua relação com a funcionalidade de estruturas variáveis. Ainda, concordamos as referidas autoras, que seja importante dar continuidade às análises de fenômenos linguísticos variáveis de modo a favorecer a

\footnotetext{
6 Projeto Porcufort - Português Oral Culto de Fortaleza - é um banco de dados gerados a partir de 62 inquéritos realizados com 73 pessoas de diferentes faixas etárias sob a coordenação do professor Dr. José Lemos Monteiro, na Universidade Estadual do Ceará, no biênio 1991-2. Os participantes são fortalezenses, em sua maioria, ou cearenses que pouco ou nunca se afastaram do Estado.

7 Há ainda que se comentar sobre os projetos de pesquisa em rede sobre a formação de Atlas Linguísticos dos diferentes falares em nosso país, como o Projeto ALiB (Atlas Linguístico do Brasil). Formado em 1996, por uma iniciativa da Universidade Federal da Bahia, juntamente com outras instituições federais e estaduais, tem por meta a realização de um atlas geral no Brasil no que diz respeito à língua portuguesa, e oferecer aos estudiosos da língua portuguesa (linguistas, lexicólogos, etimólogos, filólogos, etc.), aos pesquisadores de áreas afins (história, antropologia, sociologia, etc.) e aos pedagogos (gramáticos, autores de livros-texto, professores) subsídios para o aprimoramento do ensino/aprendizagem e para uma melhor interpretação do caráter multidialetal do Brasil. O Projeto ALiB fundamenta-se nos princípios gerais da Geolinguística contemporânea, priorizando a variação espacial ou diatópica, mas utiliza-se também dos pressupostos teóricos da Sociolinguística Variacionista. Não incluímos tais grupos em nosso levantamento, embora eles tenham sido encontrados na base de dados do CNPq e tenham conexões com alguns dos grupos aqui apresentados, por sua ênfase na variação diatópica (fônicas, morfossintáticas e léxico-semânticas) e não inclusão de estudos de variação diastrática (gênero, sexo, etc.). Entendemos, porém, que os resultados destas pesquisas também poderão contribuir para fundamentar e definir posições teóricas sobre a natureza da implantação e desenvolvimento da Língua Portuguesa no Brasil.

8 Sabemos que a base de dados do CNPq não contém informações sobre todos os trabalhos sendo desenvolvidos no país, mas optamos por essa base de dados como uma das fontes principais de nossa pesquisa uma vez que ela é um instrumento que visa proporcionar atividades de troca de informação, intercâmbio e cooperação entre pesquisadores, grupos, instituições de pesquisa e outros atores do desenvolvimento científico e tecnológico, registrando e preservando a memória da atividade de pesquisa científica e tecnológica no país. Na tentativa de suprir algumas das lacunas, as informações foram verificadas também em outras fontes, como sites oficiais de associações científicas, de programas de pós-graduação em linguística no país e de grupos de pesquisa, assim como a plataforma lattes.
} 
interação entre os diferentes grupos de pesquisa no Brasil, buscando mapear a variação linguística em nosso país, assim como visando participar da discussão teórica internacional sobre a relação entre variação e mudança linguística.

\section{CONSIDERAÇÕES FINAIS}

Neste artigo, buscamos elaborar uma retrospectiva da Sociolinguística como ciência, com especial enfoque na corrente variacionista, desde sua gênese, derivada da contradição entre sistema e mudança linguística (como uma resposta ao estruturalismo e uma busca de observar a mudança empiricamente). A partir da explanação de seu desenvolvimento, buscamos os trabalhos feitos na atualidade dentro dos microcontextos estudados por diversos grupos de pesquisa que proliferaram na vasta extensão do território brasileiro, com o intuito de fazer um levantamento que pudesse mostrar de que modo os estudos em tal área se desenvolveram a partir do ano 2000.

Esse levantamento mostrou um crescimento considerável de grupos de pesquisa situados em todas as regiões do país, mostrando que a Sociolinguística Variacionista tem ganhado espaço na discussão acadêmica na área da linguagem e também que muitos grupos mais antigos passaram agora a constituir grandes aglomerados em forma de redes de pesquisa, a fim de promover a expansão das bases de dados e contribuir para o maior fluxo de informação entre pesquisadores de diferentes instituições.

Acreditamos que a formação de redes de pesquisa e a ampla divulgação e diálogo entre os grupos constituem a base da fundamentação e definição de posições teóricas sobre a natureza do desenvolvimento da língua portuguesa e das diferentes comunidades de fala no contexto brasileiro, permitindo a constituição de uma base sólida de conhecimentos que possam informar a perspectiva aplicada e a formulação de políticas públicas que levem em consideração uma visão plural de língua e sociedade no Brasil.

\section{REFERÊNCIAS}

CARBONI, F. Introdução à Linguística. Belo Horizonte: Autêntica, 2008.

CEZARIO, M.M.; VOTRE, S. Sociolinguística. In: MARTELLOTA, M.E. (Org.). Manual de Linguística. São Paulo: Contexto, 2008. p. 141-155.

GUY, G.R.; ZILLES, A.M.S. O ensino da língua materna: uma perspectiva sociolinguística. Calidoscópio, v. 4, n. 1, p. 39-50, jan./abr. 2006.

. Sociolinguística quantitativa - instrumental de análise. São Paulo: Parábola Editorial, 2007.

LABOV, W. Padrões sociolinguísticos. Tradução de Marcos Bagno, Maria Marta Pereira Scherre, Caroline Rodrigues Cardoso. São Paulo: Parábola Editorial, 2008 [1972].

MOLLICA, M.C. Fundamentação teórica: conceituação e delimitação. In: MOLLICA, M.C.; BRAGA, M.L. (Orgs.). Introdução à Sociolinguística: o tratamento da variação. 2. ed. São Paulo: Contexto, 2004. p. 9-14.

; RONCARATI, C.N. Questões teórico-descritivas em Sociolinguística e em Sociolinguística Aplicada e uma proposta de agenda de trabalho. D.E.L.T.A., v. 17, n. esp., p. 45-55, 2001.

MONTEIRO, J.L. Para compreender Labov. 2. ed. Petrópolis: Vozes, 2000.

NARO, A.J. Modelos quantitativos e tratamento estatístico. In: MOLLICA, M.C.; BRAGA, M.L. (Orgs.). Introdução à Sociolinguística: o tratamento da variação. 2. ed. São Paulo: Contexto, 2004.

PAIVA, M.C.; SCHERRE, M.M.P. Retrospectiva Sociolinguística: contribuições do PEUL. D.E.L.T.A., v. 15, n. esp., p. 201-232, 1999.

PAULSTON, C.B.; TUCKER, G.R. History of sociolinguistics: introduction. In: Sociolinguistics: the essential readings. Malden: Blackwell Publishing, 2003. 
SHUY, R.W. A brief history of American Sociolinguistics 1949-1989. In: PAULSTON, C.B.; TUCKER, G.R. (Eds.). Sociolinguistics: the essential readings. Malden: Blackwell Publishing, 2003. p. 4-16.

WEINREICH, U.; LABOV, W.; HERZOG, M. Fundamentos empíricos para uma teoria da mudança linguística. Tradução de Marcos Bagno. São Paulo: Parábola, 2006 [1975].

Recebido em 24/07/11. Aprovado em 14/o9/11. 